\title{
Clinical outcome of bonded partial indirect posterior restorations on vital and non-vital teeth: a systematic review and meta-analysis
}

\author{
Mario Dioguardi ${ }^{1} \cdot$ Mario Alovisi $^{2} \cdot$ Giuseppe Troiano $^{1} \cdot$ Carlo Vito Alberto Caponio $^{1} \cdot$ Andrea Baldi $^{2}$. \\ Giovanni Tommaso Rocca ${ }^{3} \cdot$ Allegra Comba $^{2} \cdot$ Lorenzo Lo Muzio $^{1} \cdot$ Nicola Scotti $^{2}$
}

Received: 22 April 2021 / Accepted: 20 September 2021 / Published online: 10 October 2021

(c) The Author(s) 2021

\begin{abstract}
Objectives The survival rate of indirect partial adhesive restorations on vital versus endodontically treated teeth is still controversial. The hypothesis is that there may be a difference in the survival rate of partial adhesive restorations performed on non-vital teeth compared to vital teeth.

Materials and methods This systematic review was conducted following the PRISMA guidelines. The considered clinical studies investigated the outcomes of adhesive inlays, onlays, and overlays conducted over the past 40 years, focusing on Kaplan-Meier survival curves to calculate the hazard ratio (primary objective) and the survival rate (secondary objective) between vital and non-vital teeth. The risk of bias was assessed using the Newcastle-Ottawa Scale. Studies included in the review were identified through bibliographic research on electronic databases ("PubMed," "Scopus," "Cochrane Central Register of Controlled Trial," and "Embase"). The $K$ agreement between the two screening reviewers was evaluated.

Results A total of 55,793 records were identified on PubMed, Scopus, and other bibliographic sources, and after the application of the eligibility and inclusion criteria, eight articles were included for qualitative analysis and six for quantitative analysis. The meta-analysis of the primary and secondary outcomes demonstrated that hazard ratios $(\mathrm{HR}=8.41,95 \% \mathrm{CI}$ : $[4.50,15.72])$ and survival rates $(\mathrm{OR}=3.24,95 \% \mathrm{CI}:[1.76,5.82])$ seemed more favorable for indirect partial adhesive restorations on vital teeth than for those on endodontically treated teeth.

Conclusions Within the limits of this study, these findings suggest that the risk of failure of indirect partial adhesive restorations on endodontically treated teeth is higher than on vital teeth.

Clinical relevance The use of partial adhesive restorations on vital and endodontically treated teeth showed different longterm clinical outcomes.
\end{abstract}

Keywords Dental restoration failure $\cdot$ Inlay $\cdot$ Onlay $\cdot$ Overlay $\cdot$ Survival rates $\cdot$ Endodontically treated teeth

\section{Introduction}

The clinical failure of adhesive restorations still raises strong interest in the scientific literature, especially when endodontically treated teeth (ETT) are considered. In particular, it is

Nicola Scotti

nicola.scotti@unito.it

1 Department of Clinical and Experimental Medicine, University of Foggia, Via Rovelli 50, 71122 Foggia, Italy

2 Department of Surgical Sciences, Dental School, University of Turin, Via Nizza 230, 10100 Turin, Italy

3 Division of Cariology and Endodontology, University Clinics of Dental Medicine, University of Geneva, Geneva, Switzerland important to identify the most frequent causes of failure to better prevent their long-term occurrence. The main sources of direct or indirect restoration failure in vital or endodontically treated teeth are found in biological and mechanical causes, such as secondary caries, hypersensitivity, pulp pathology, chronic and acute apical periodontitis, tooth and root fractures, ceramic or resin composite chipping, and loss of retention or adhesion [1]. However, failures may have completely different clinical implications: they can lead to a re-intervention that aims at tooth healing and consequent maintenance or to tooth loss.

In vital posterior teeth, the annual restorative failure rate could vary from 1 to $3 \%$ in medium- and large-size cavities, while the failure rate may range from 2 to $12.4 \%$ in endodontically treated teeth [2-4]. da Rosa Rodolpho et al. concluded 
that, during a 17 -year monitoring period, $5.1 \%$ of restored teeth needed replacement due to endodontic reasons, which could negatively contribute to the reduction of the tooth survival rate [5]. Indeed, recent studies have reported that posterior tooth longevity mainly depends on the amount of remaining tooth structure and the variation of the physical-mechanical properties of the dentin over years [6-8]. Thus, the efficacy of restorative procedures in preserving sound teeth and minimizing root tissue loss is crucial [9].

In the past, there was the opinion that ETT needed a root canal post and full coverage crown rehabilitation [10, 11]. Aquilino and Caplan showed that cuspal coverage could increase up to six times the survival rate of non-vital posterior teeth [12]. Therefore, the full crown has been considered the gold standard therapeutic approach for large cavities in ETT for years [13]. However, full crown preparations tend to remove a large amount of healthy dental tissue from teeth that have already lost a huge quantity of sound tooth structure due to pathology and endodontic procedures [14]. Hence, the majority of recent studies have focused more on partial direct or indirect bonded restorations, which ensure higher sound tissue preservation than traditional fixed full crowns $[15,16]$. As a consequence of this paradigm shift, direct and indirect partial bonded restorations, such as inlays, onlays, overlays, and endocrowns, have been proposed for the rehabilitation of ETT as valid therapeutic alternatives to conventional prosthetic solutions [17-20].

Regarding bonded partial indirect restorations on vital and non-vital teeth, the data emerging from the literature are partially merged and sometimes in contrast. A previous study reported that the 11-year success rate of inlays and onlays is $80 \%$ [21], while Skupien et al. showed that among a population of 69 inlays, only two failed, leading to extraction of the dental element, with a whole success rate of $85.5 \%$ at 9 years [22]. However, Reiss et al. after a follow-up of 16.7 years reported 28 failures out of 77 ETT with a survival rate of $63 \%$ [23]. Furthermore, Vagropoulou et al. investigated the survival of inlays and onlays versus complete coverage restorations, finding an overall 5-year rate of $90 \%$ [24]. Systematic reviews have repeatedly investigated the survival of inlays, onlays, and overlays. Morimoto et al. reported a survival rate of $92-95 \%$ for glass-reinforced ceramics and feldspathic porcelains at 5 years and $91 \%$ at 10 years, without distinction between vital and non-vital teeth, identifying the main failure cause as fracture/chipping of the restoration material [25]. Recently, Sampaio et al. reported the survival rate of the CAD/CAM inlays as 97\% after 5 years and $89 \%$ after 10 years. In particular, the rate was $95 \%$ after 5 years for pressable ceramics, and for stratified ceramics, it was $88 \%$ after 5 years and $93 \%$ after 10 years [26]. However, previous systematic reviews, with or without meta-analyses, did not investigate the survival rate of partial indirect bonded posterior restorations on vital teeth compared with ETT. Thus, the present study null hypothesis is that there is no difference in the survival rate of partial indirect adhesive restorations performed on non-vital teeth compared to vital teeth.

\section{Materials and methods}

The following systematic review was conducted based on the indications of the Preferred Reporting Items for Systematic Reviews and Meta-Analyses (PRISMA) statement [27] and was registered in PROSPERO: CRD42020204095.

The study was constructed on the population, intervention, control, and outcome (PICO) questions: patient (patients who need restorative treatment with inlay, onlay, and overlay on ETT), intervention (inlay, onlay, and overlay), control (patients with inlay, onlay, and overlay on vital teeth), and outcome (hazard ratio and survival rate for inlay, onlay, and overlay between vital and non-vital teeth); a scientific question was asked: What is the hazard ratio of failure of indirect partial restorations in ETT compared to those placed on vital teeth?

\section{Eligibility criteria}

The considered clinical studies investigated the survival rate of adhesive inlays, onlays, and overlays published in English and conducted over the past 40 years. We decided to focus on the last 40 years due to partial restoration manufacturing techniques that have undergone a profound change from gold casts to more recent CAD-CAM techniques. Investigating clinical studies with follow-ups published before 1980 would have led to an increase in heterogeneity, with a high risk of bias. Bibliographies of previously published systematic reviews on similar topics were checked to find articles for potential inclusion in this study.

After an initial screening of abstracts identified on the evaluated databases, the potentially eligible articles were qualitatively evaluated to investigate the survival rate of inlays, onlays, and overlays on both vital and ETT, focusing on the research of the studies that reported hazard ratios or Kaplan-Meier survival curves to allow the calculation of the hazard ratio of vital to non-vital teeth. The potentially eligible articles were eventually subjected to a full-text analysis to verify their eligibility for inclusion in both qualitative and quantitative analyses.

The inclusion and exclusion criteria applied in the fulltext analysis were as follows:

- Includes all articles that report data on the inlays, onlays, and overlays hazard ratio between vital and non-vital teeth or the Kaplan-Meier survival curves (primary outcome); 
- Includes all studies that report data on survival and success rates of inlays, onlays, and overlays on non-vital teeth (secondary outcome);

- Excludes all studies and articles that do not report data on the survival of partial adhesive restorations on ETT; studies reporting data on the same sample already investigated in previous studies; are published in a language other than English; are published prior to 1979; with a high risk of bias.

\section{Research and screening methodology}

Studies included in the review were identified through bibliographic research on electronic databases. The literature search was conducted on the search engines "PubMed," "Scopus," "Cochrane Central Register of Controlled Trial," and "Embase." The database search was conducted between June 1, 2020, and June 9, 2020, and the last search for a partial update of the literature was conducted on July 18 , 2021. The details regarding the search terms and combination strategies used in the literature review are reported in Table 1.

The keywords for the search and their combinations were decided before the identification phase by common agreement between two reviewers (with the task of selecting potentially eligible articles). Overlaps were removed through the use of EndNote 8.0.

The records obtained were subsequently examined by two independent reviewers (M.D. and M.A.) and a third reviewer (G.T.) acted as a decision-maker in situations of doubt.

The screening included an analysis of the title and the abstract to eliminate records not related to the topics of the review. After the screening phase, complete texts of the articles were analyzed, from which the ones eligible for the qualitative analysis and the inclusion in the meta-analysis for the two outcomes were identified. Data sought by the three reviewers in the included studies were as follows:

(1) Primary outcome: Hazard ratio between inlays, onlays, and overlays indirect adhesive restorations on non-vital and vital teeth (reviewers sought Kaplan-Meier survival curves for inlays on vital and non-vital teeth).

(2) Secondary outcome: Survival rate of inlays, onlays, and overlays indirect adhesive restorations on vital and non-vital teeth (the reviewers searched for all failures regarding inlays, onlays, and overlays on vital and nonvital teeth).

The $K$ agreement between the two screening reviewers was 0.84 [29]. The $K$ agreement was based on the formulas in the Cochrane handbook for systematic reviews of interventions [30].

\section{Statistical analysis protocol}

The protocol used for the meta-analysis was based on the indications of the Cochrane handbook for systematic reviews of interventions (Chapter 11, Sect. 11.3.2).

To calculate the hazard ratio for the log hazard ratio and the variance in the included articles that did not report the data, the value was extracted using the Tienery method [31] using the software Engauge Digitizer and the Microsoft Excel spreadsheet created by Matt Sydes for the extraction of summary statistics of literature published for survival endpoints [32].

The extraction of the data and the reporting methods used follow the indications of the Cochrane handbook for systematic reviews of interventions Chapter 7 (Selection of Studies and Data Collection), specifically from pages 152 to 182 [30]. The data extraction, performed by two independent reviewers, is summarized and reported in the tables in the "Results" section and subsequently included in the statistical analysis programs.

The software Reviewer Manager 5.4 (Cochrane Collaboration, Copenhagen, Denmark) was used for the meta-analysis, and in particular for pooled hazard ratio, pooled odds ratios $(\mathrm{OR})$, confidence intervals, and inverse of variance.

The Newcastle-Ottawa Scale for case-control studies was used to assess the risk of bias in the included studies in primary and secondary outcomes [33]. The risk of bias assessment for the included articles was conducted by three reviewers, two of whom independently rated the articles, while in case of disagreement, a third reviewer comes to discuss it.

The presence of heterogeneity was assessed by calculating the Higgins index $\left(I^{2}\right)$; if such a measure proved to be higher than $50 \%$, the rate of heterogeneity was considered high. Pooled results of the meta-analysis are represented as forest plots for each of the analyzed outcomes.

We used the GRADE pro-Guideline Development Tool online software (GRADEpro GDT, Evidence Prime, Hamilton, $\mathrm{ON}$ ) to evaluate the quality of evidence.

\section{Results}

A total of 1621 records were identified on PubMed, Scopus, and other bibliographic sources (reference of systematic reviews concerning the topics of inlays, onlay, and overlays, Table 1). After screening and applying the eligibility and inclusion criteria, the following eight articles were included for qualitative analysis and six for quantitative analysis:

- Five articles for the primary outcome: Beier et al. 2012 [34], van Dijken et al. 2010 [35], Reiss et al. 2006 [23], Bresser et al. 2019 [36], Stoll et al. 2010 [37]. 


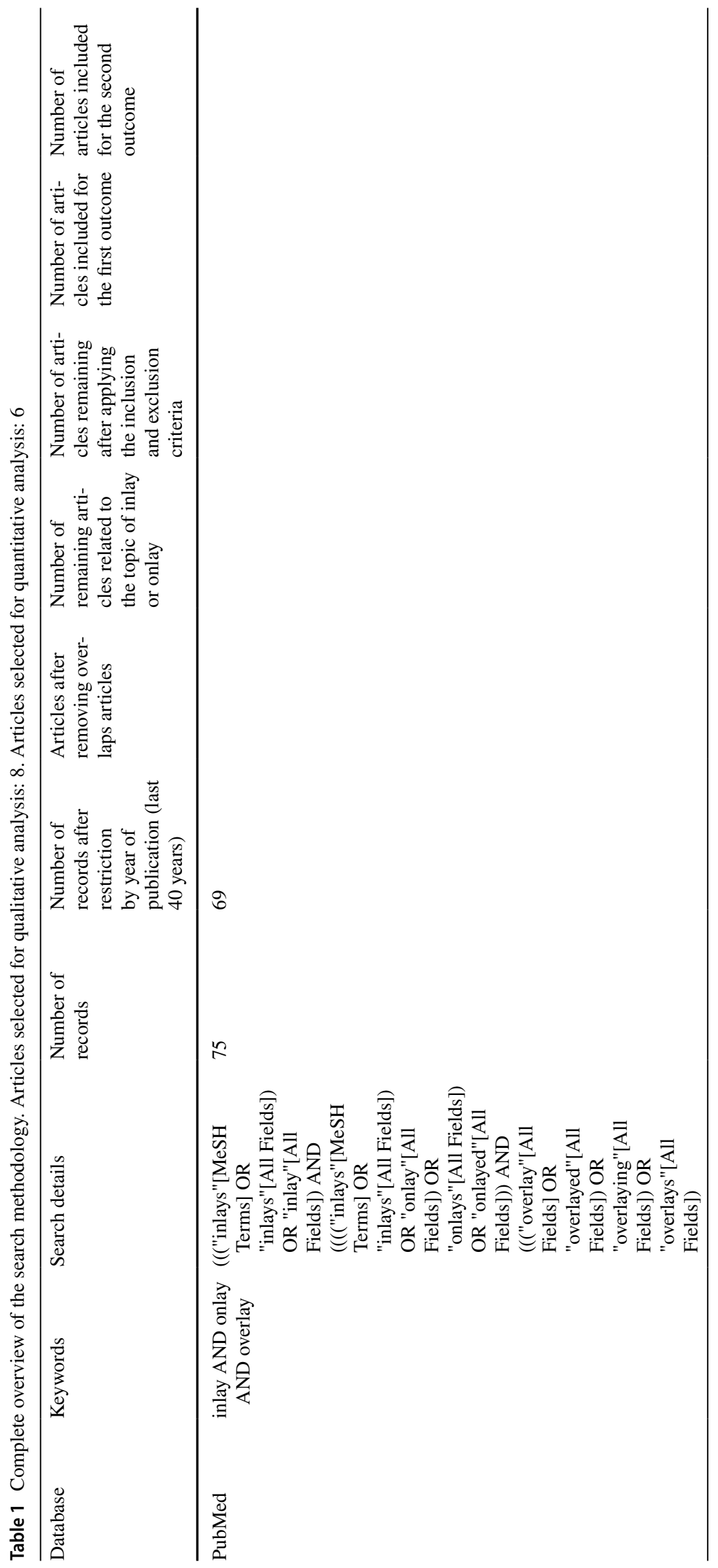




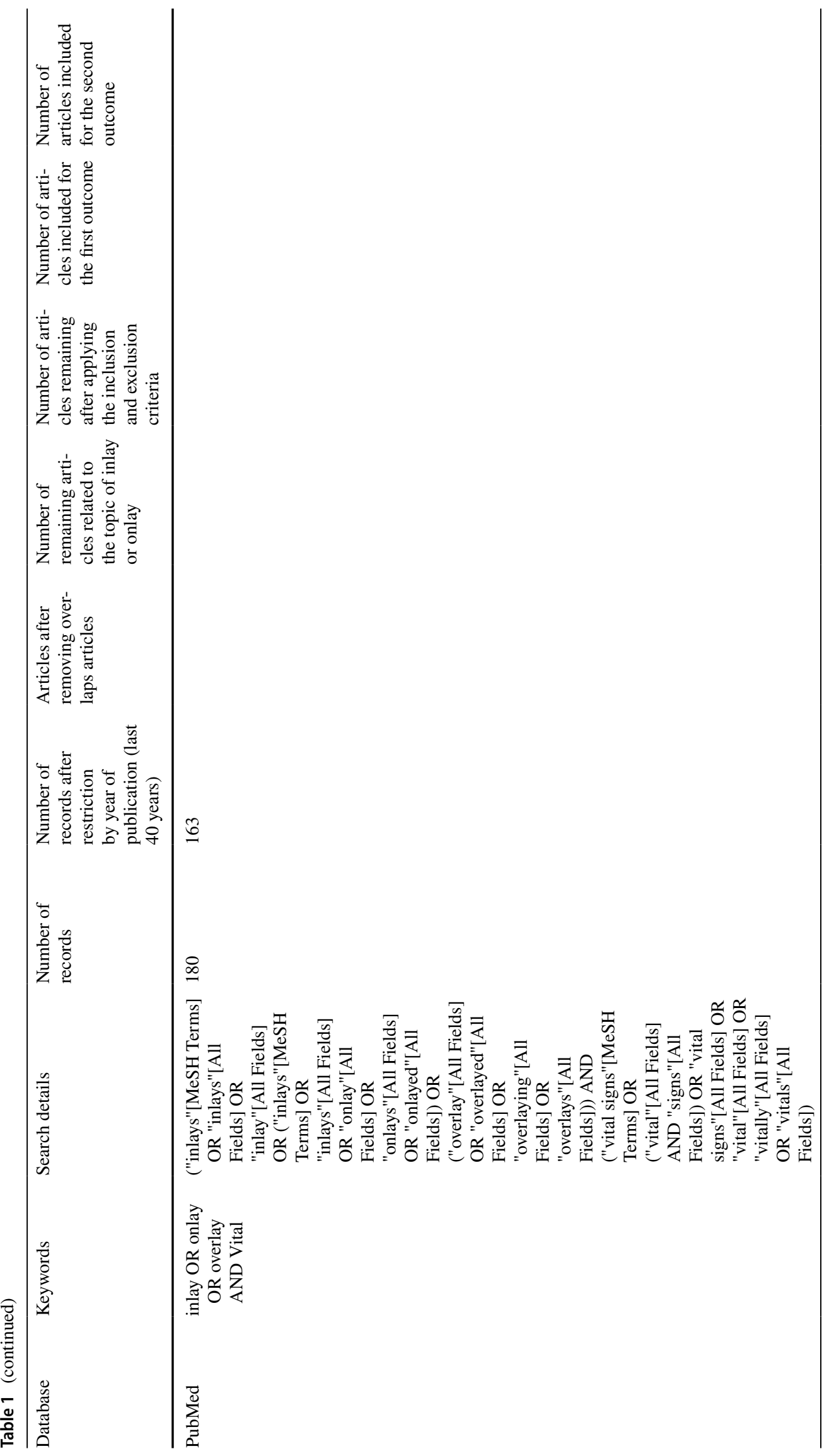




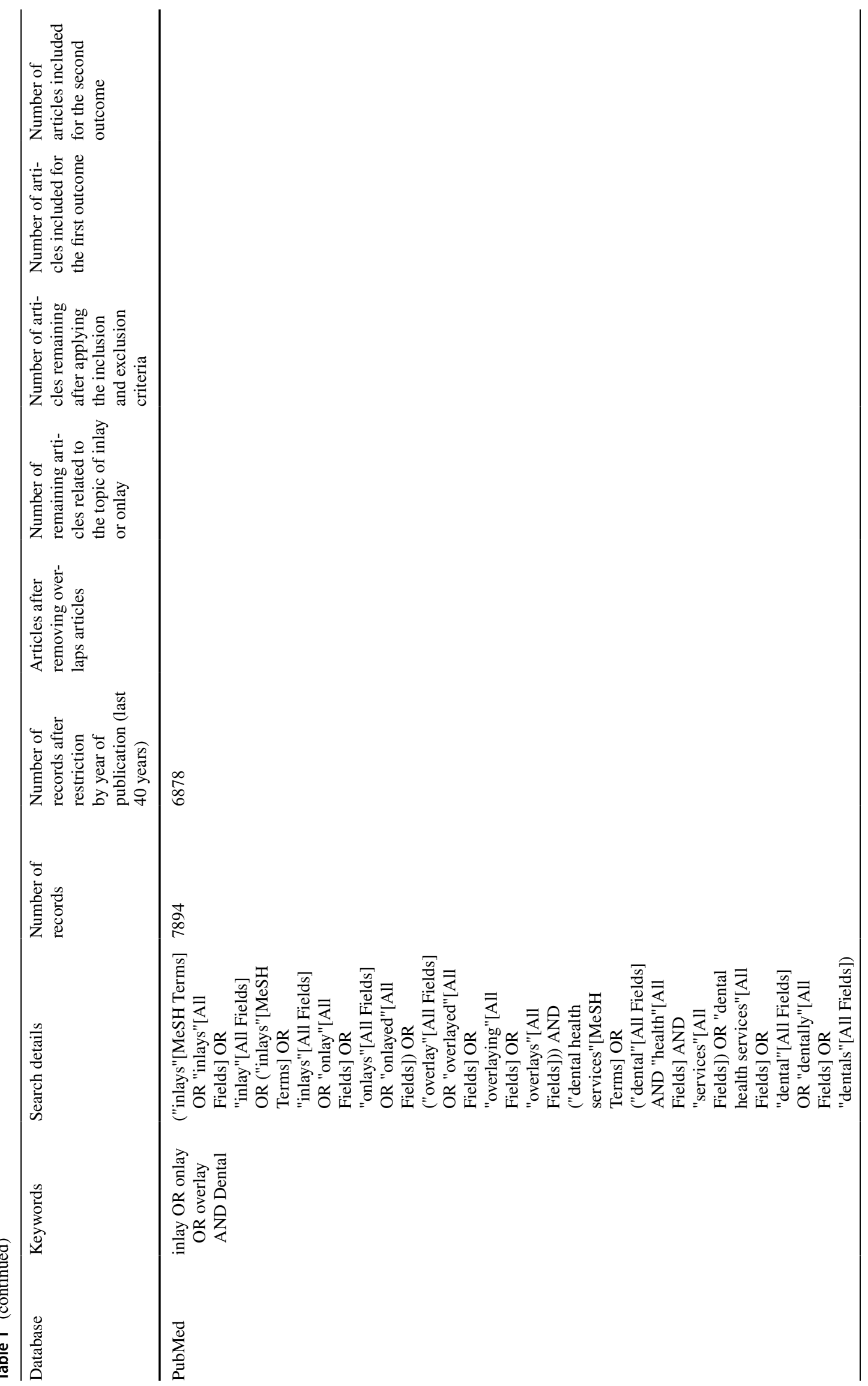




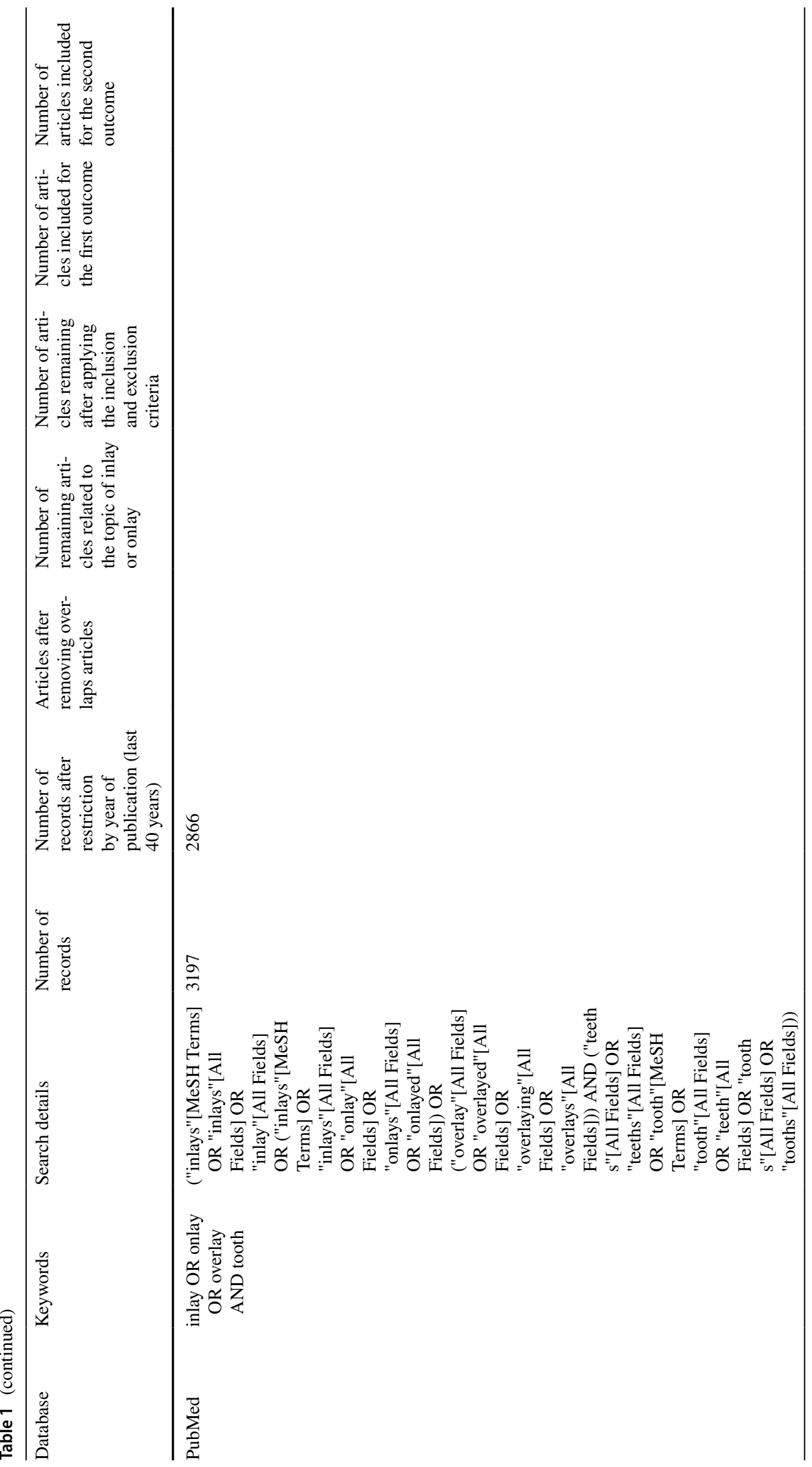




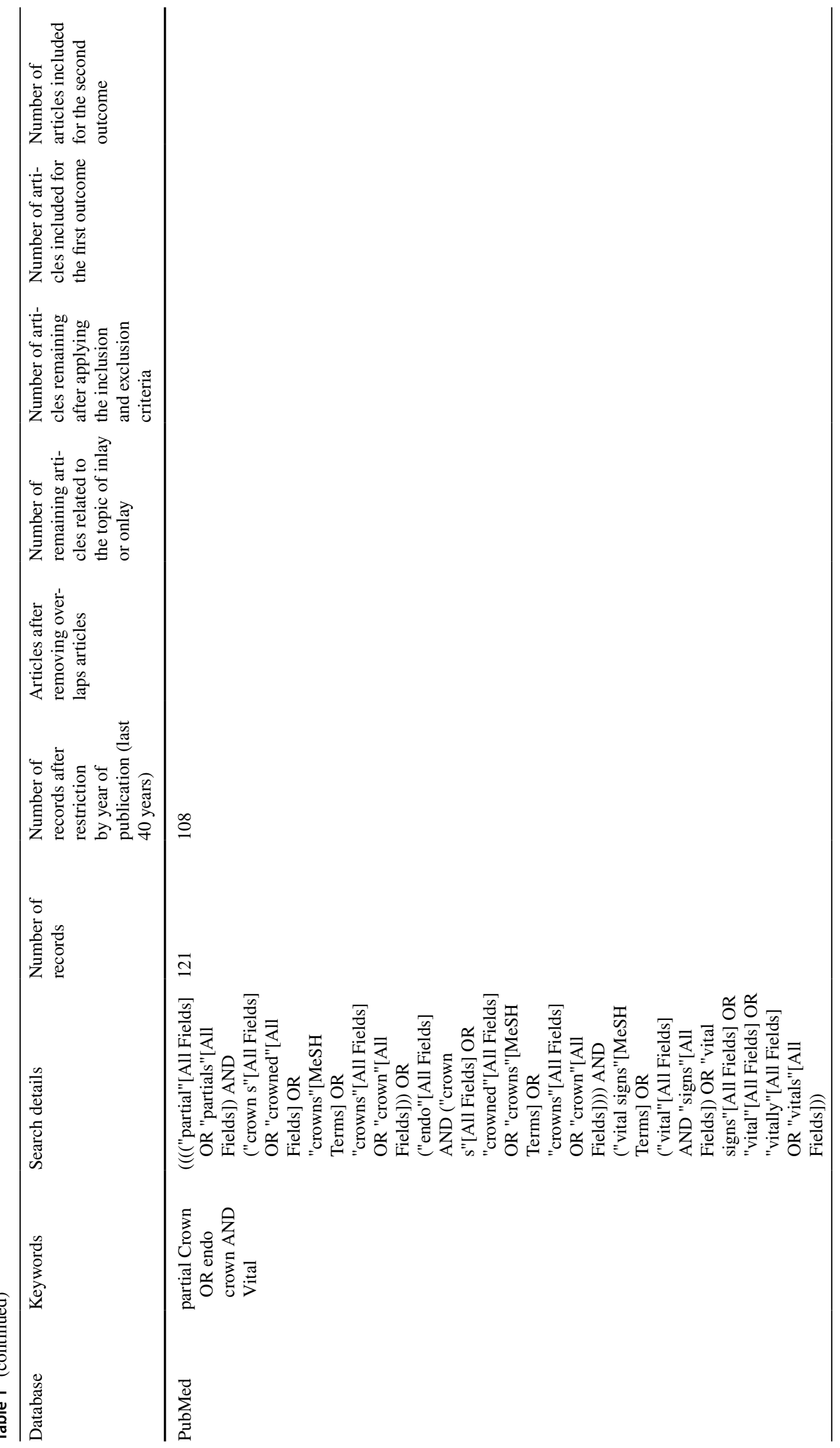




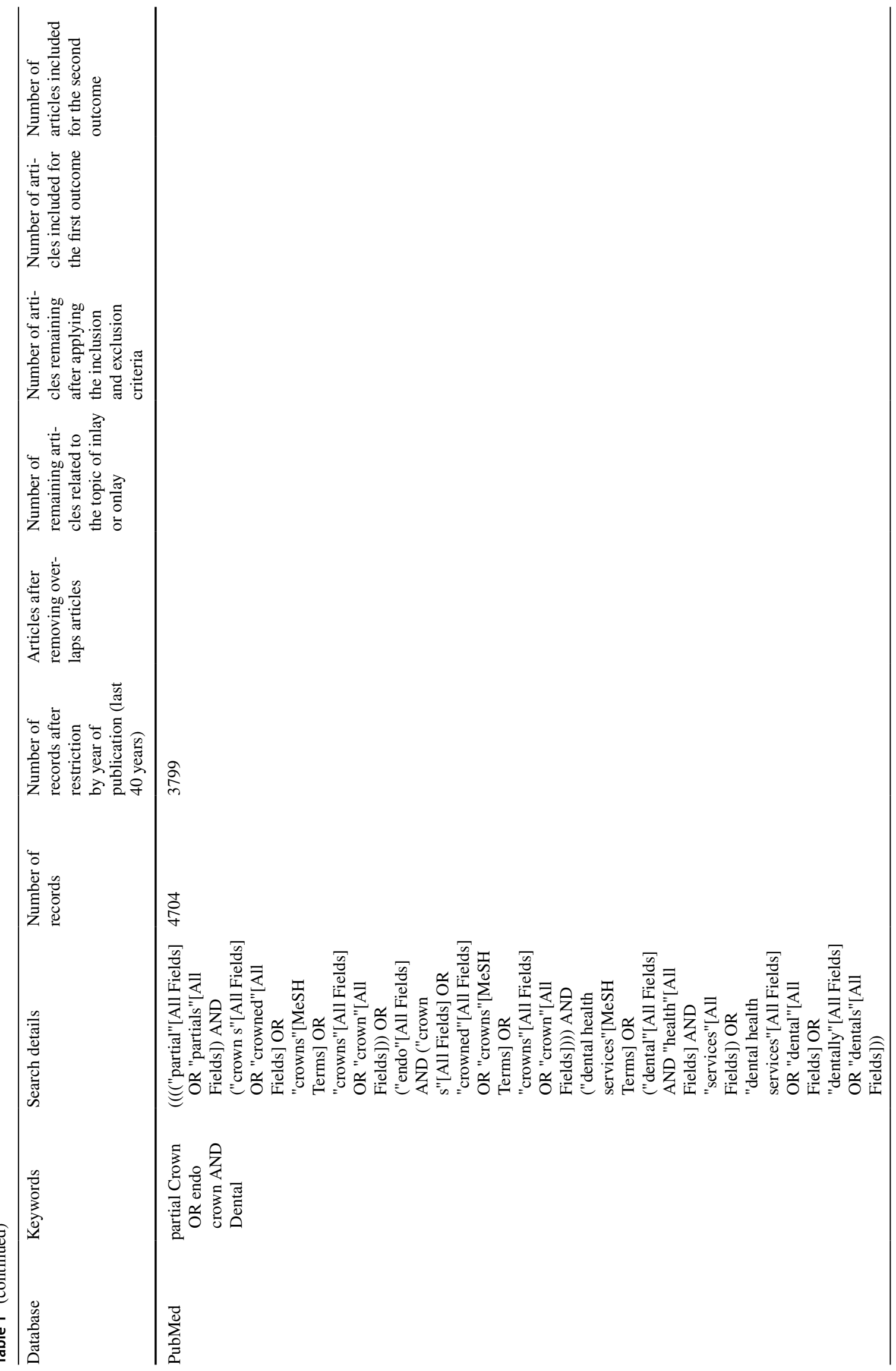




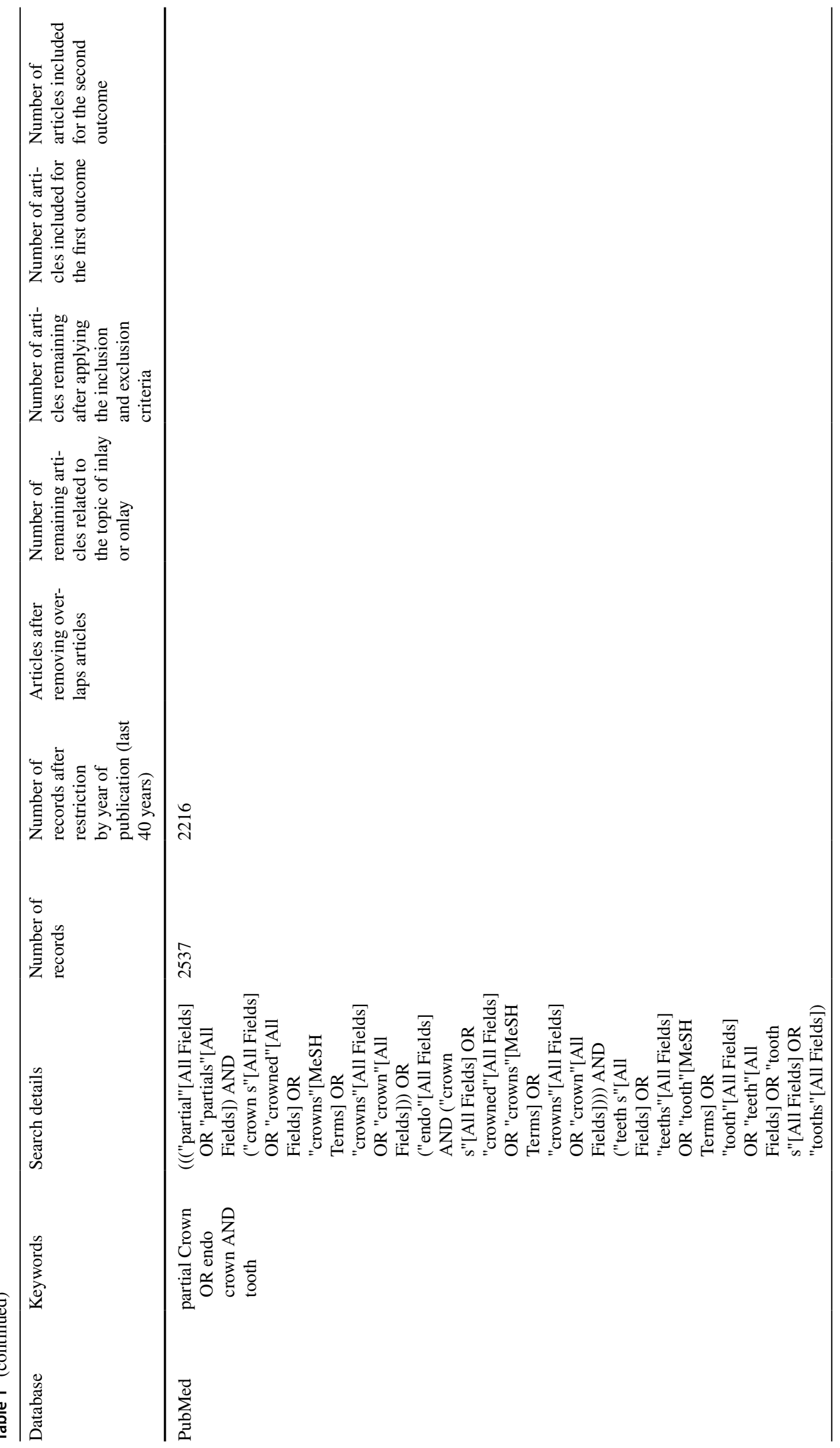




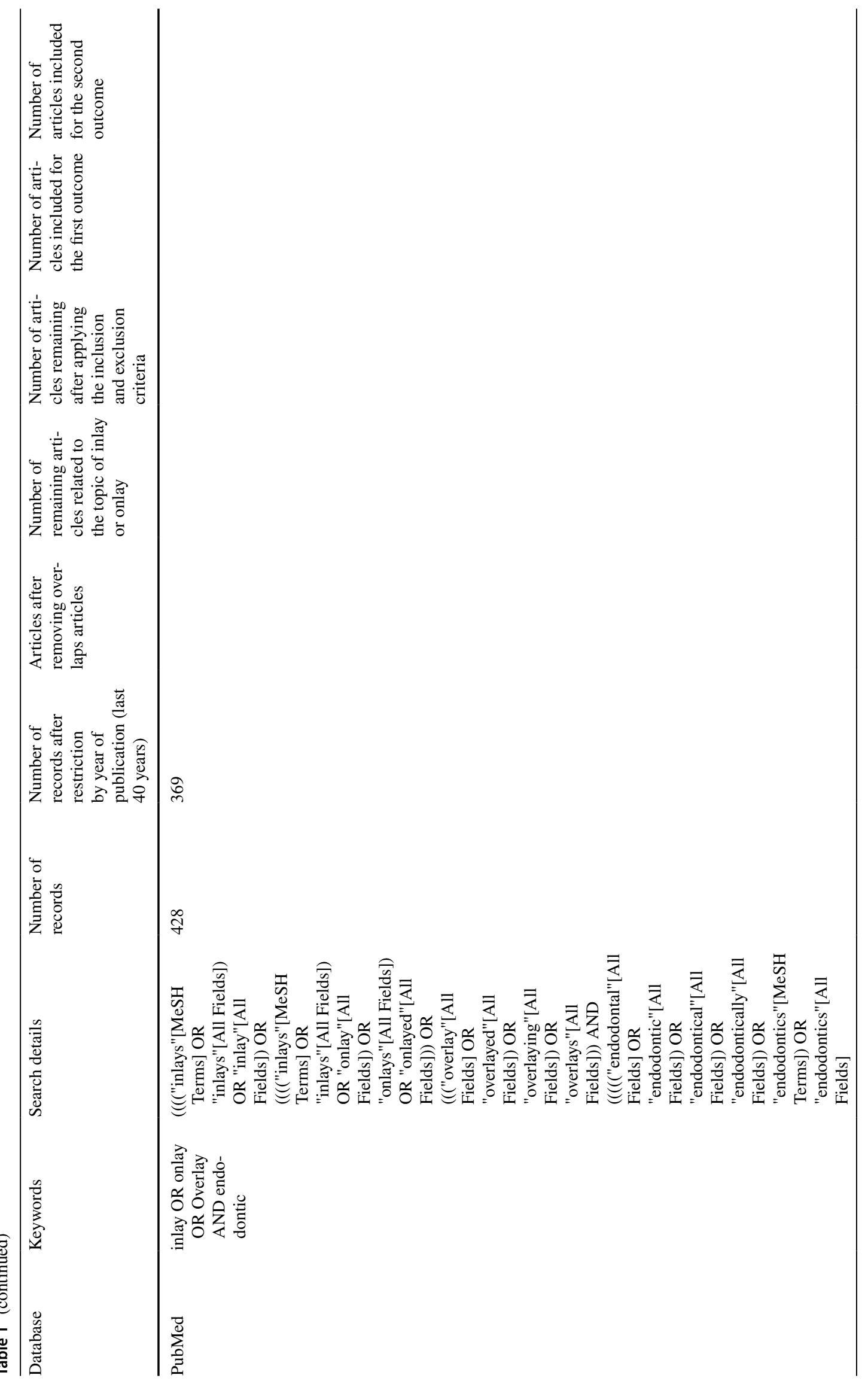




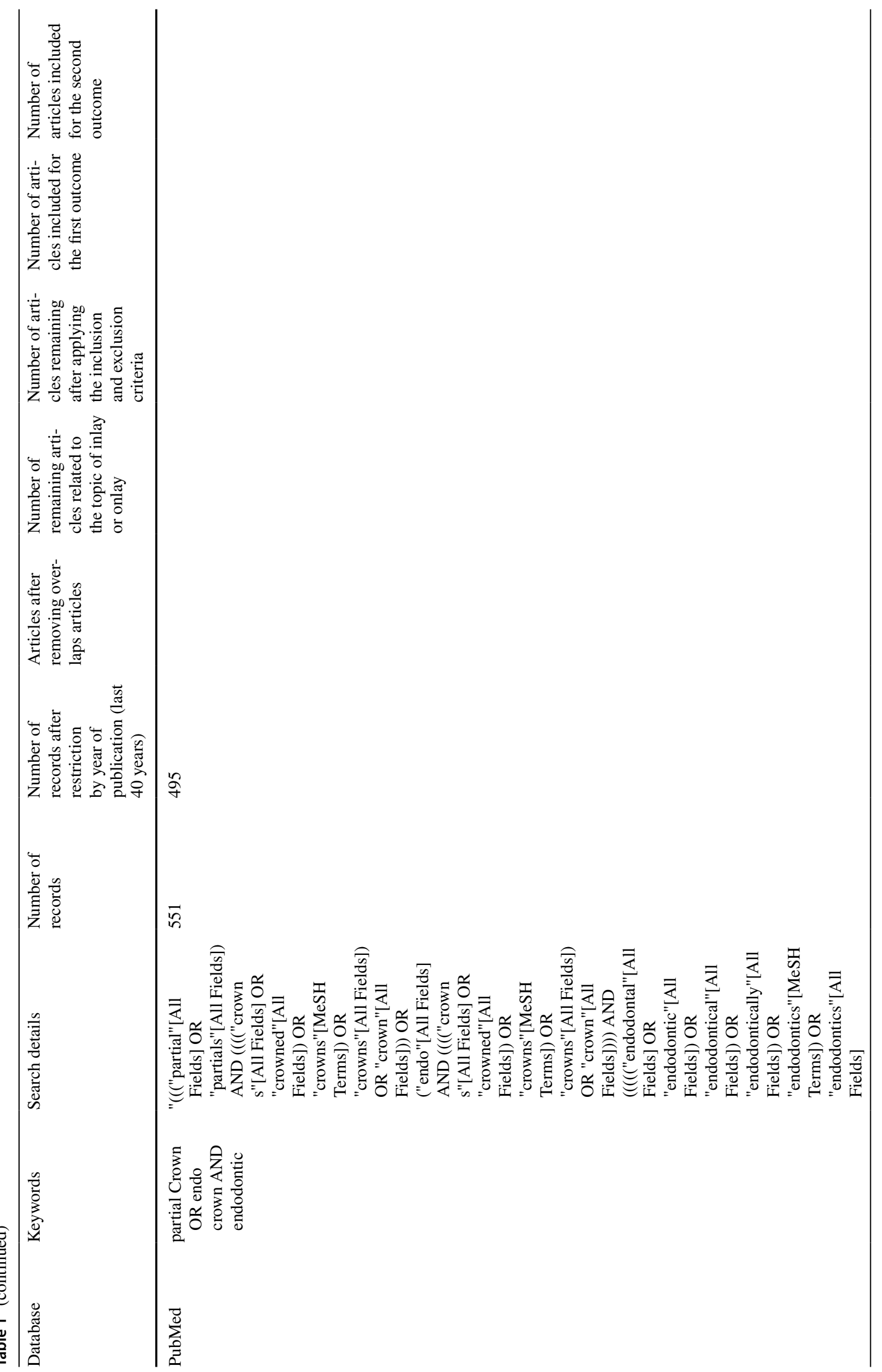




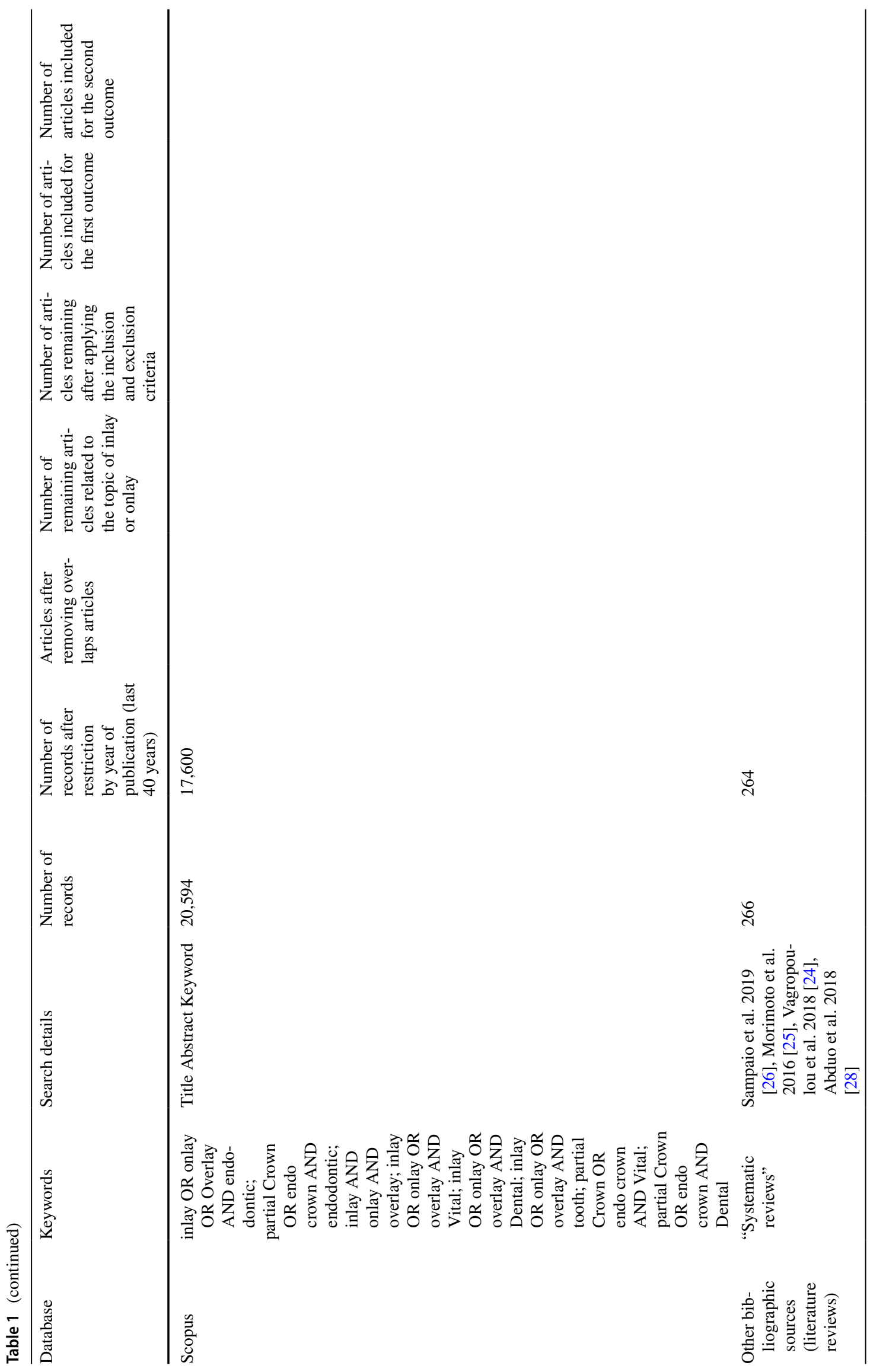




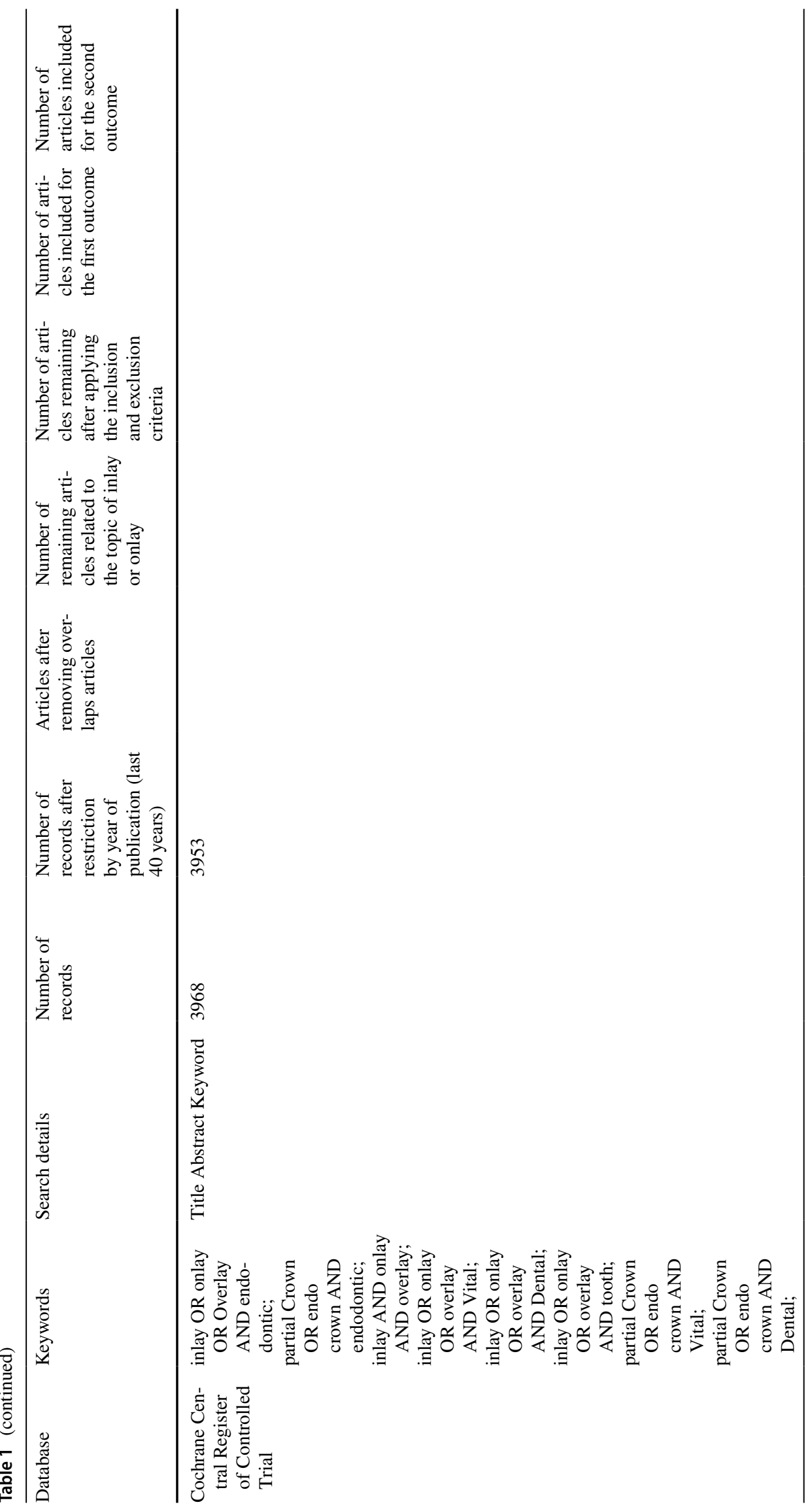




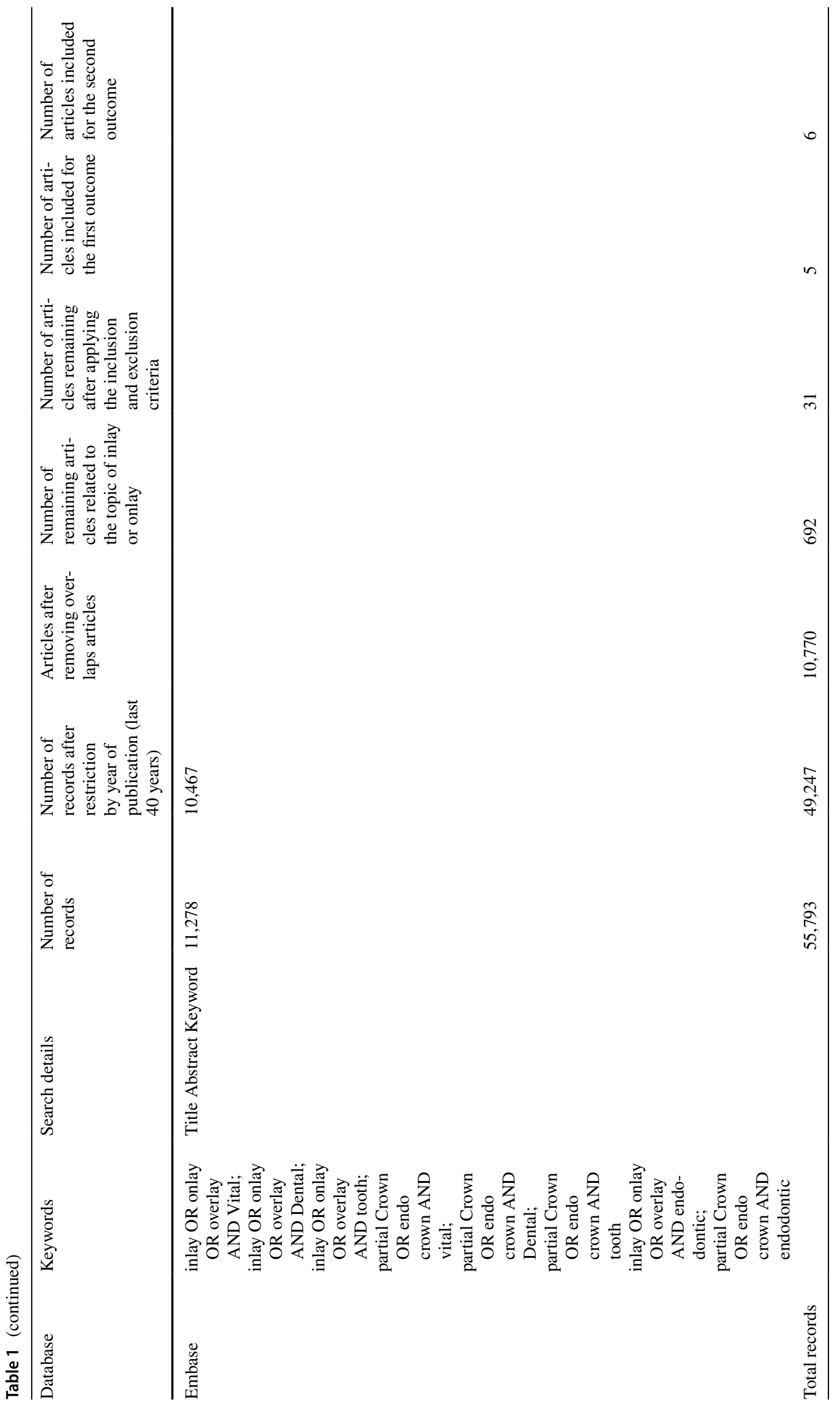


- Six articles for the secondary outcome: Beier et al. 2012 [34], van Dijken et al. 2010 [35], Reiss et al. 2006 [23], Bresser et al. 2019 [36], Stoll et al. 2010 [37], Schulte et al. 2005 [38].

- Two articles were included only for qualitative analysis: Homsy et al. 2015 [39], Studer et al. 2000 [40].

The entire selection and screening procedures are described in the PRISMA flowchart (Fig. 1).

\section{Study characteristics and data extraction}

The data that have been extracted from the included studies include the journal (year of publication, first author); the type of clinical study conducted (retrospective, prospective, observational, randomized clinical trial, case-control); the type of rehabilitation performed (inlays, onlays, overlays) and the material (porcelain, glass ceramic, composite, lithium disilicate); the period of inclusion and the average follow-up of the patients; the number of inlays, onlays, and overlays performed on vital and non-vital teeth; and the number of failures. Furthermore, the hazard ratios of vital to ETT were extracted, and images of the survival curves of the indirect restorations were acquired. The data extracted for the two outcomes are reported in Tables 2 and 3.

\section{Risk of bias}

The risk of bias was assessed through the Newcastle-Ottawa Case-Control Scale, modified by the authors, as demonstrated in previous systematic reviews with meta-analysis $[41,42]$. The results are reported in Table 3. For each category, a value of one to three was assigned (one $=$ low and three $=$ high).
Fig. 1 Flowchart of the different phases of the systematic review

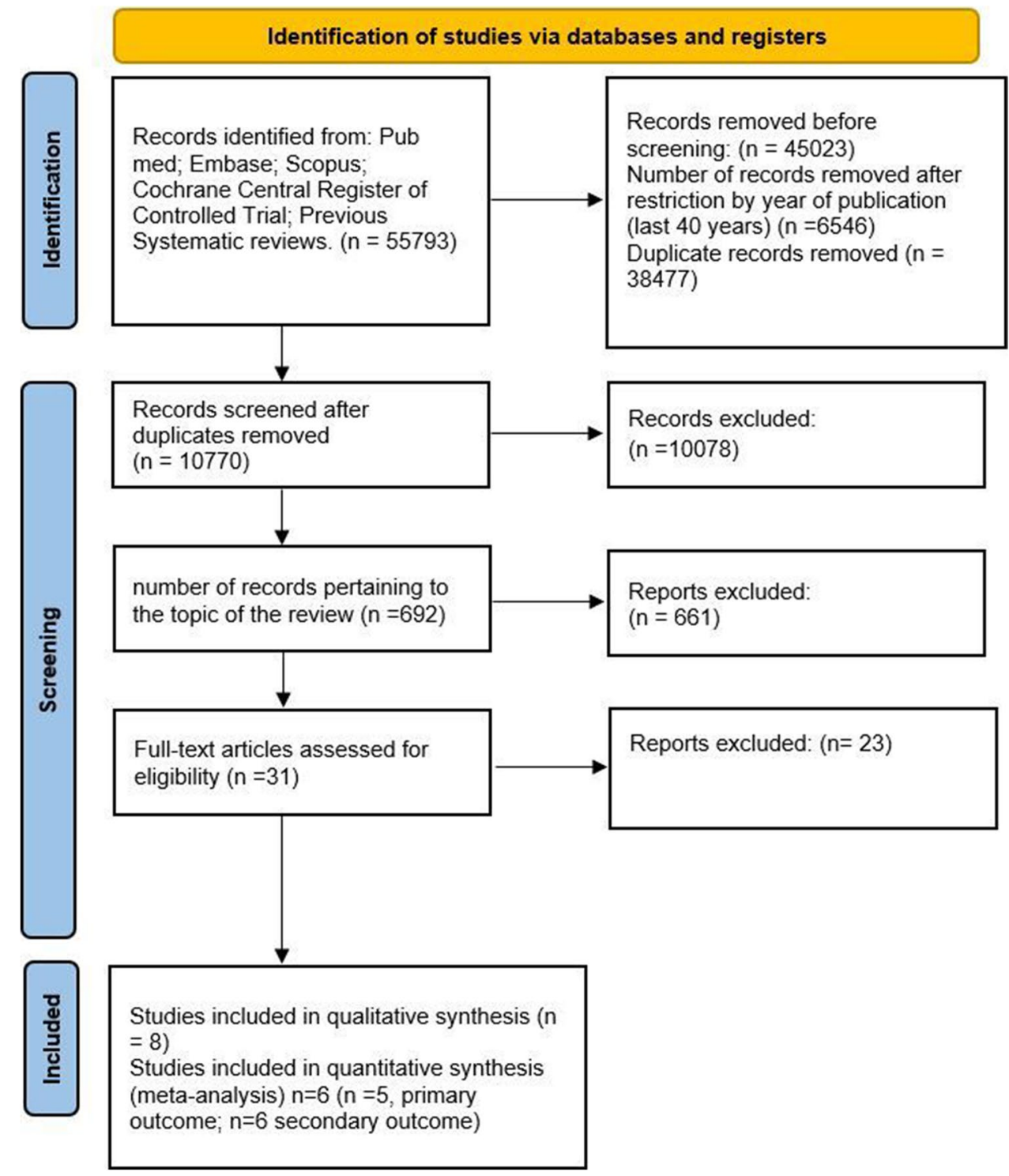




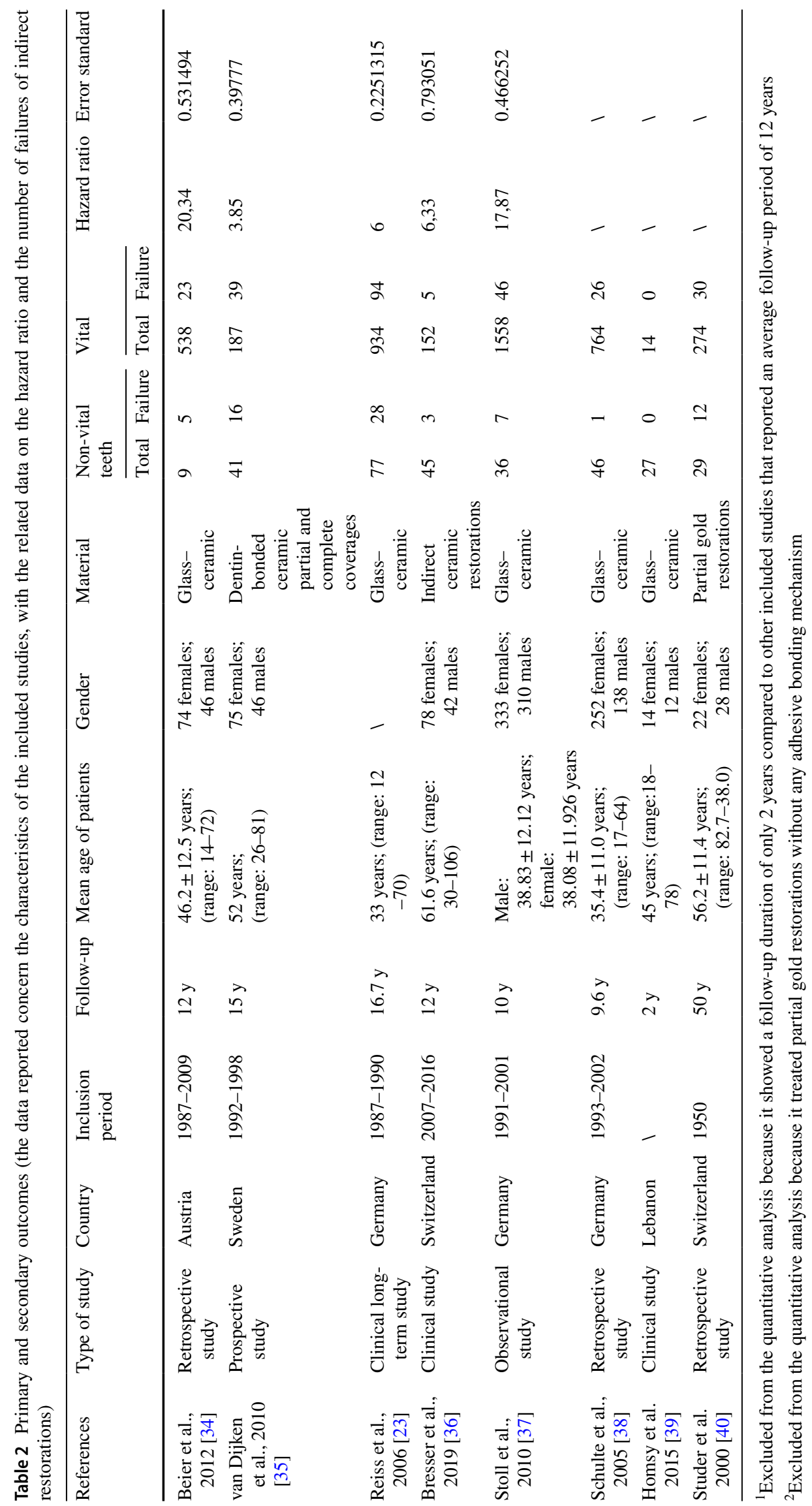




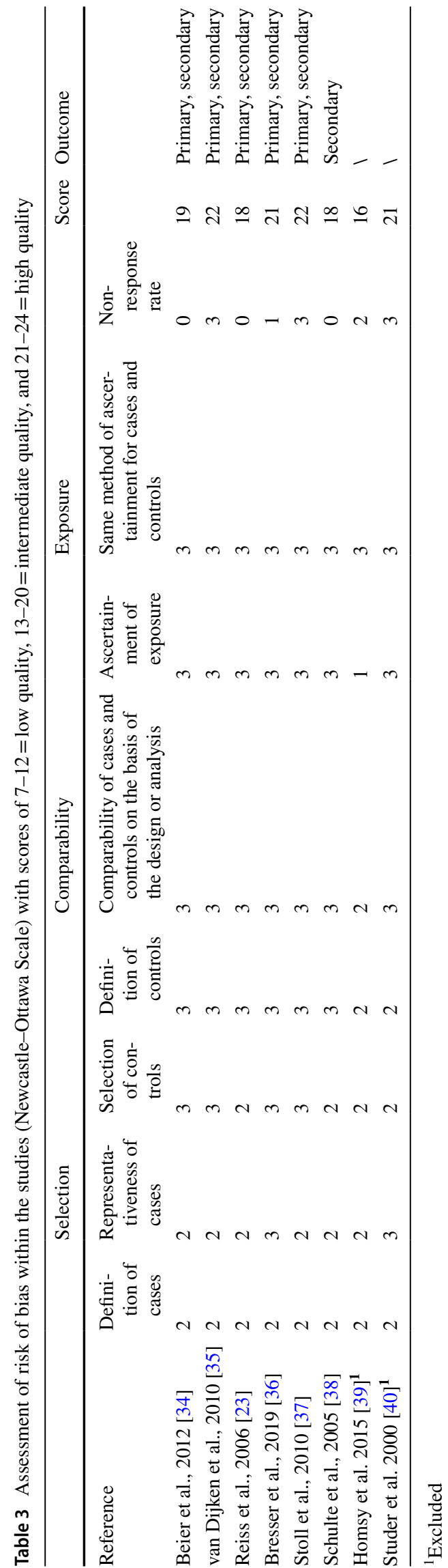

Studies presenting a high risk of bias were not included in the meta-analysis. Articles with a high risk of bias were excluded from the scale and eliminated during the inclusion phase. Other articles were excluded due to the investigated outcomes or because they presented the same data and samples. The bias risk assessment for the eight included articles was conducted by M.D., G.T., and M.A.

The heterogeneity that emerged from the meta-analysis was average; for the first outcome, we had an $I^{2}$ of $68 \%$ and for the second outcome, a heterogeneity with an $I^{2}$ of $50 \%$. Acceptable heterogeneity values were also confirmed by a funnel plot for the first two outcomes (Fig. 2).

The study by Homsy et al. (2015) [39] was excluded from the quantitative analysis because it showed a follow-up duration of only 2 years compared to other included studies that reported an average follow-up period of 12 years. The study by Studer et al. (2000) [40] was excluded from the quantitative analysis because it treated partial gold restorations without any adhesive bonding mechanism. Therefore, the inclusion would have been a source of bias.

The authors also used GRADE pro-GDT to evaluate the quality of the primary outcomes and secondary outcomes (Table 4). The results suggested that the quality of evidence is moderate for the first outcome and high for the second outcome.

\section{Meta-analysis}

The meta-analysis of the primary outcome (hazard ratio between inlays, onlays, and overlays on vital and ETT) showed heterogeneity with $I^{2}$ of $63 \%$ (random effects model was applied). The results reported in the forest plot showed that the hazard ratio seemed more favorable for indirect partial adhesive restorations on vital teeth than for those on ETT $(\mathrm{HR}=8.41,95 \%$ CI: $[4.50,15.72])$ (Fig. 3).

In addition, an analysis of the subgroups was conducted based on the type of restoration. Subgroup: inlay ; Subgroup: overlaylonlaylinlay (Fig. 4). The results reported for the first subgroup (inlay) (HR $=9.59,95 \%$ CI: [3.33, 27.66], for the second subgroup (overlaylonlaylinlay) $(\mathrm{HR}=7.78,95 \% \mathrm{CI}$ : [2.56, 23.67]), confirmed the same trend.

The meta-analysis of the secondary outcome (survival rate of inlays, onlays, and overlays on non-vital and vital teeth) showed heterogeneity with $I^{2}$ of $55 \%$ (random effects model was applied). The results reported in the forest plot indicated that the pooled odds ratio seemed more favorable for indirect partial adhesive restorations on vital teeth than for those on ETT $(\mathrm{OR}=3.24,95 \%$ CI: [1.76, 5.82]) (Fig. 5).

The analysis of the 2 subgroups reported the following results: Subgroups inlay (OR $=5.71,95 \%$ CI: $[3.67,8.88])$; Subgroup overlaylonlaylinlay $(\mathrm{OR}=2.01,95 \% \mathrm{CI}$ : [1.15, 3.51]) (Fig. 6). 

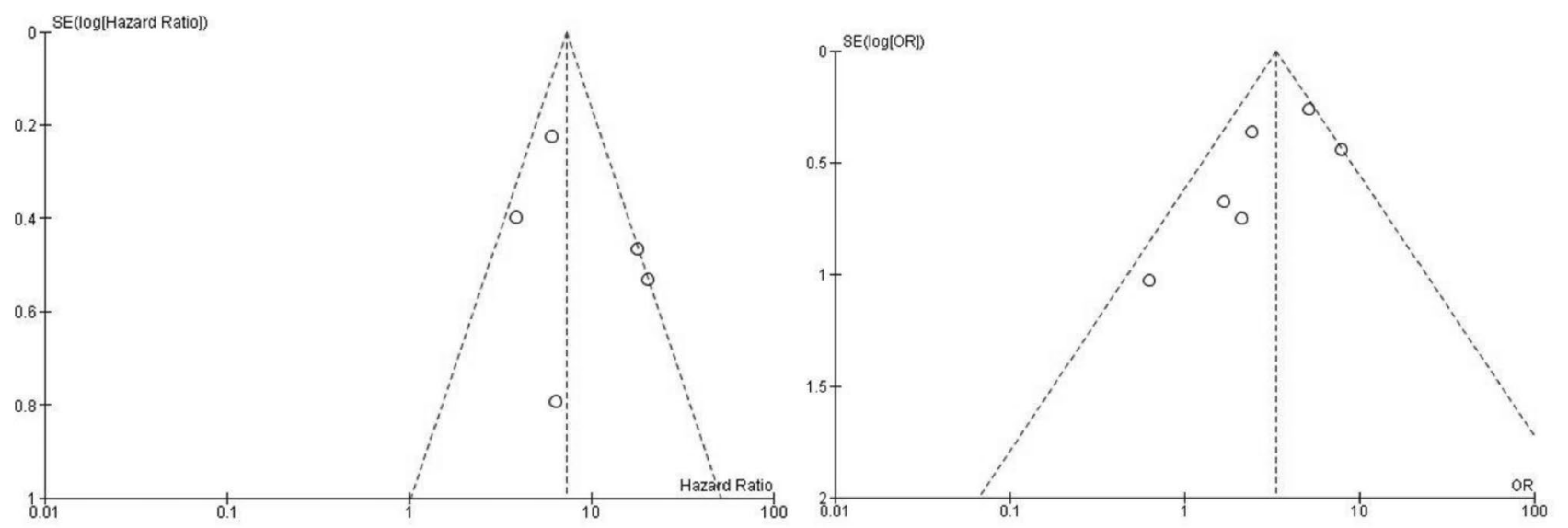

A

Fig. 2 Funnel plots of the evaluation of heterogeneity for the (A) primary and (B) secondary outcomes

\section{Discussion}

Indirect adhesive solutions represent an increasingly used restorative option and deserve scientific interest that certifies their clinical effectiveness in the rehabilitation of vital and non-vital teeth. It is important to note that an indirect adhesive solution on a vital tooth is necessary in cases in which a dental element is affected by destructive carious lesions or coronal fractures that compromise a large portion of it [5]. In these cases, the tooth triggers defense processes toward the pulp organ, which alters its histological composition, especially at the level of deep dentin [43]. Matrix metalloproteinases (MMPs) can be induced by dentinal demineralization and polymorphonuclear neutrophil inflammatory response to invading microorganisms [44]. However, MMPs may have a detrimental effect on dentinal bonding, contributing to the degradation of the hybrid layer $[45,46]$.

The loss of pulpal vitality opens the door to a further series of histological and structural alterations that may strongly affect the longevity of an adhesive indirect restoration. The ETT are weakened after root canal treatment and should ideally be covered with indirect partial or full restorations [47]. The amount of remaining tooth structure, the marginal ridge maintenance, the functional occlusal forces, and the quality of the dentin substrate have significant associations with the longevity of the coronal restoration [48-50].

According to a retrospective cohort study, the overall survival rates of ETT without crown coverage at 1, 2, and 5 years are $96 \%, 88 \%$, and $36 \%$, respectively [47]. Therefore, the placement of an indirect restoration should be strongly recommended for posterior ETT [51]. Nevertheless, the cuspal coverage of vital teeth affected by large II class or MOD cavities with reduced residual dentin thickness could be considered beneficial for long-term prognosis [52].

A full crown restoration remains the most proven solution in the literature, showing high longevity with the biological cost of a more invasive dental preparation [14, 53]. According to modern literature, the sacrifice of a less sound tooth structure in preparing a partial adhesive indirect restoration compared with full crown coverage may be a determinant for the long-term tooth prognosis [14, 53, 54]. Nowadays, the modern adhesive systems allow a minimally invasive approach both for vital and ETT teeth, with the purpose of preserving tooth tissues and protecting dental health, while simultaneously restoring esthetic and function [55].

Therefore, less invasive bonded partial restorations, such as onlays and overlays, have been suggested as valid treatment options for ETT $[17,56]$. Recent studies have reported that their longevity depends directly on the amount of remaining tooth structure and the efficacy of restorative procedures in replacing fracture structural integrity [57]. Hence, studies continue to focus more on partial adhesive restoration, which ensure higher sound tissue preservation than classic fixed full crowns that require additional removal of sound tooth tissue [55].

In this scenario, direct resin composite restorations represent the least invasive approach possible. To date, resin composites have reached a deep improvement, with the goal of increasing biomechanics behavior and, in conjunction with effective bonding techniques [58], reducing the need for indirect adhesive restoration. However, resin composites still have some limitations in terms of mechanical properties. The clinical outcomes of direct resin composite restorations vary in the literature, ranging from catastrophic to acceptable [59, 60]. Nevertheless, even when maintaining as much dental tissue as possible, clinical results are seriously influenced by the maintenance of long-term proper adhesion [61]. However, the adhesive systems may have different behaviors on non-vital enamel and dentin substrates [62-64]. Moreover, previous studies demonstrated that the cervical region enamel may negatively influence the bonding quality compared to occlusal or mid-coronal enamel, 


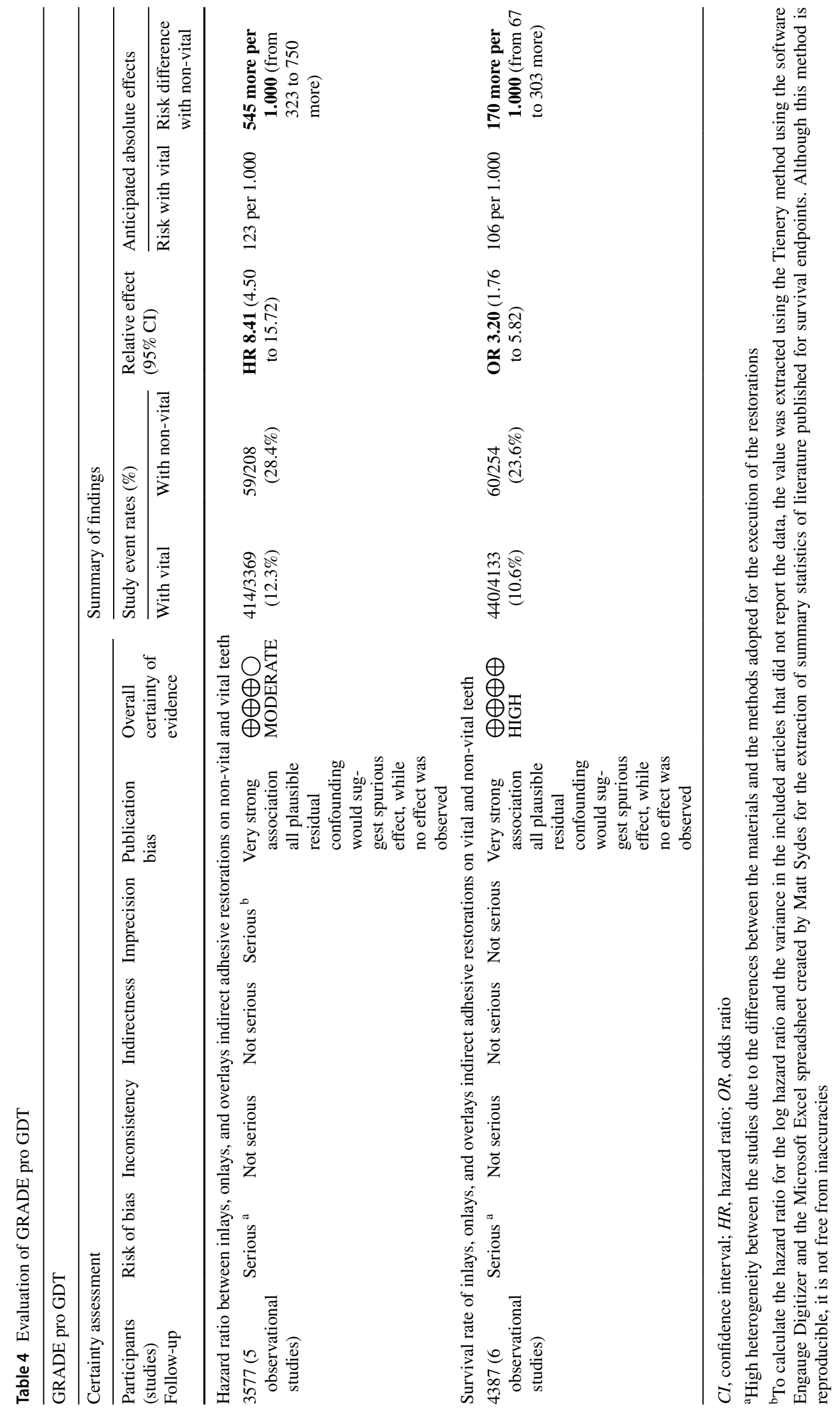


Fig. 3 A forest plot of the metaanalysis of the primary outcome

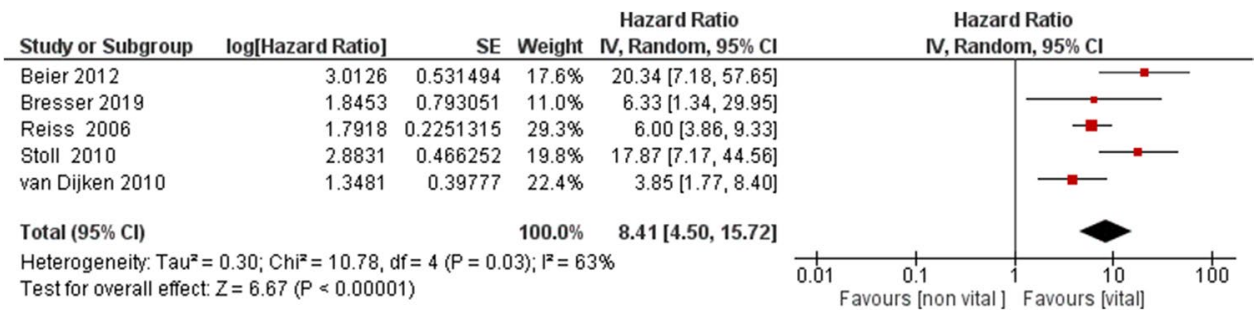

Hazard Ratio

Hazard Ratio

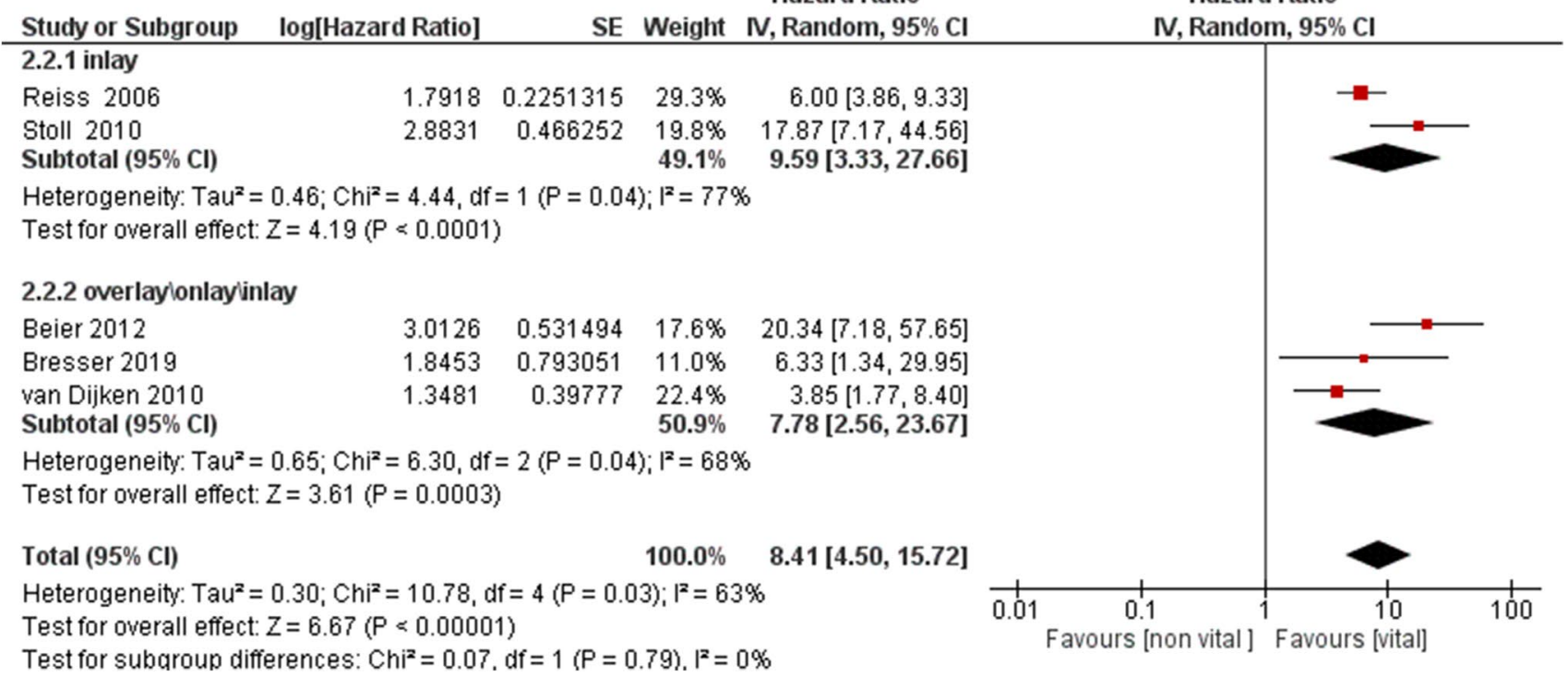

Fig. 4 A forest plot of the analysis of the subgroups of the primary outcome

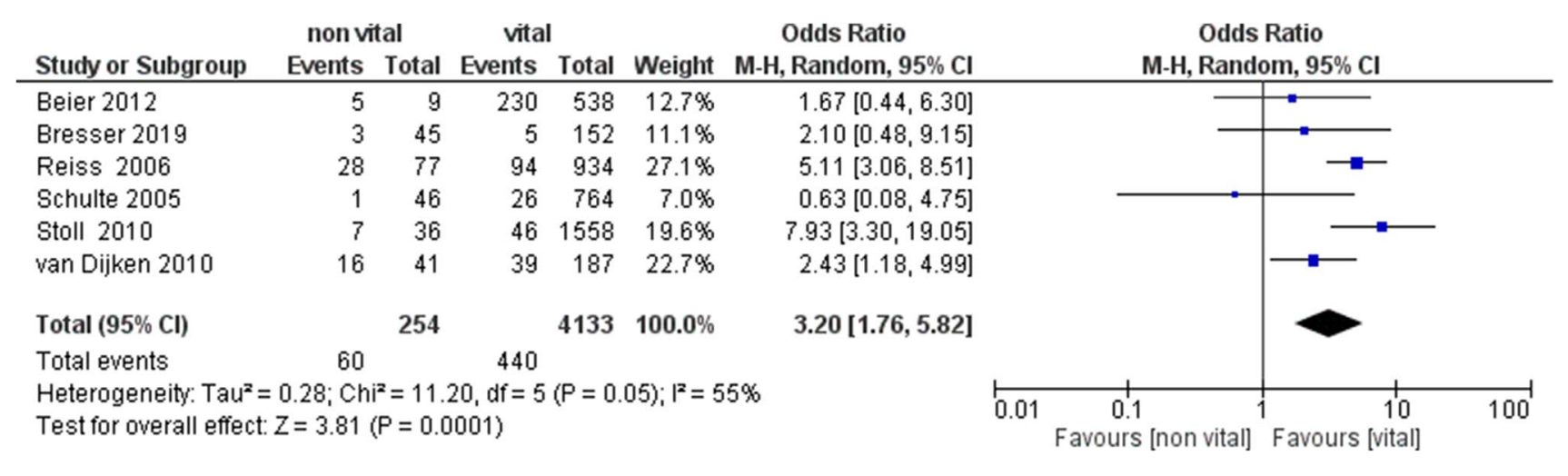

Fig. 5 A forest plot of the meta-analysis of the secondary outcome

which appears less vulnerable to micro-leakage [65]. Thus, the longevity of indirect partial adhesive restorations on ETT has been investigated, highlighting the influence of several peculiar factors on long-term outcomes, such as the quantity and quality of the remaining dental tissues [66].

These factors may represent an important difference between vital and non-vital teeth, leading to possible clinical consequences related to the quantity and quality of enamel and dentin substrates [67]. Recently, different technologies and materials have been proposed for the creation of these types of partial adhesive restorations, such as CAD-CAM systems and composite or ceramic materials [68]. Therefore, one of the main objectives of this systematic review was to investigate the survival rate of partial indirect bonded restorations on posterior vital and endodontically treated teeth. 


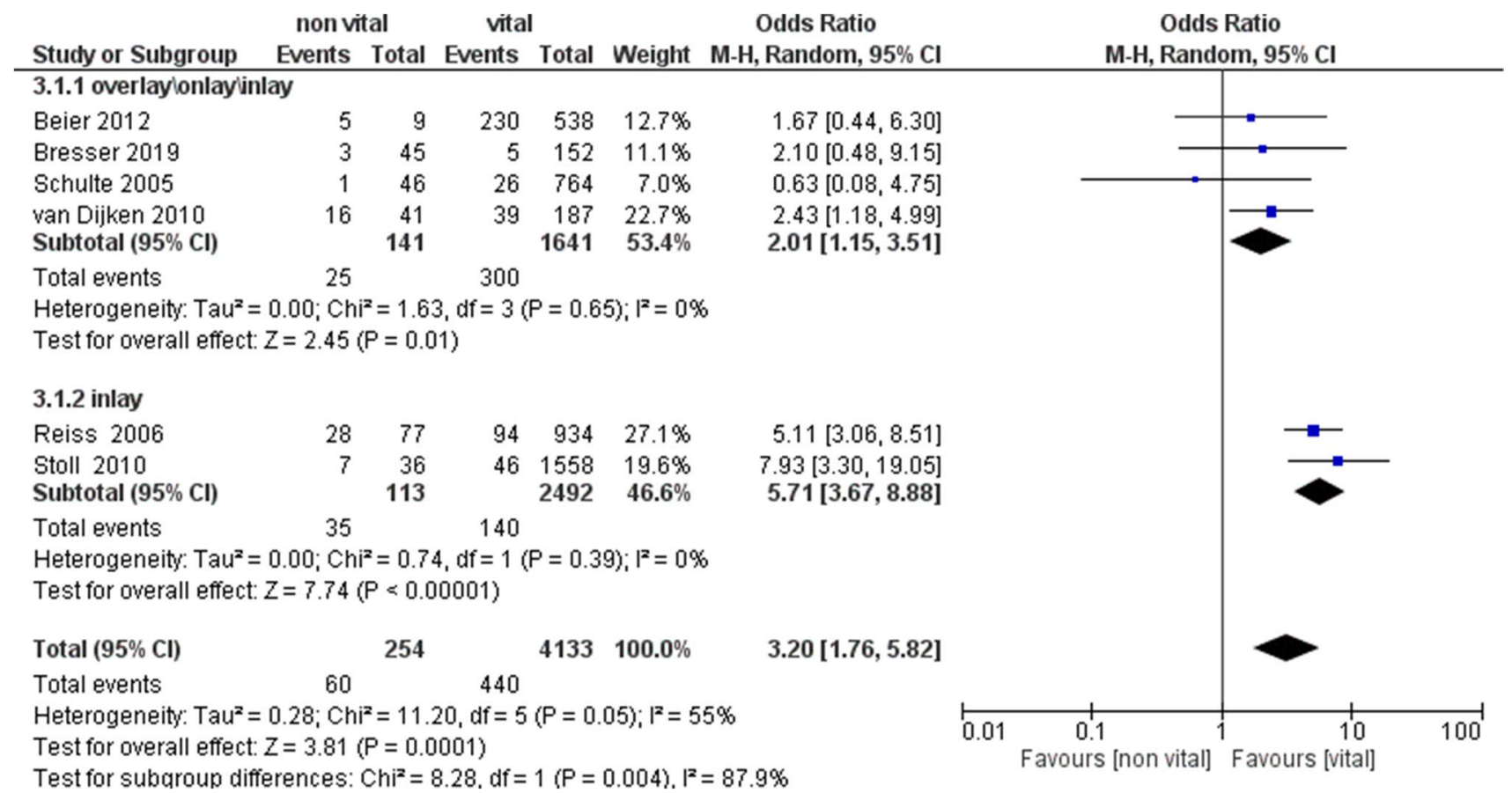

Fig. 6 A forest plot of the analysis of the subgroups of the secondary outcome

The present study showed that partial adhesive restorations seemed more favorable on vital teeth than on ETT; thus, the initial null hypothesis was rejected.

The limitations of this meta-analysis could be found in the homogeneity of the included studies: they were not randomized prospective clinical trials that directly compared the survival rates of indirect adhesive restorations. The follow-ups did not have the same duration and ranged from a minimum of 9.5 years to a maximum of 16.7. Moreover, the materials with which the indirect restorations were made are not always the same. These differences are all sources of heterogeneity. The inclusion of these studies was based on previous meta-analyses conducted on the topic but with different outcomes. From the qualitative and quantitative analyses, it emerged that the studies comparing the failure rates of inlays, onlays, and overlays on vital and non-vital teeth were only eight.

Moreover, data regarding long-term outcomes were often missing and divergent. The 2010 study by van Dijken et al. reported a prospective study with an average 15-year followup for partial ceramic coverages and described 16 failures out of 41 in non-vital teeth compared with 39 out of 186 in vital ones [35]. Reiss et al. (2006) reported the highest odds ratio of inlay failures in 28 out of 77 teeth compared with 94 out of 934 in vital teeth [23]. Apparently, Schulte et al. (2005) reported slightly different data: the odds ratio was 0.66 , although in the forest plot (Fig. 4), the data was not statistically significant where the confidence intervals intersected the line of non-effect [38]. Similarly, Beier et al.
(2012) [34] and Bresser et al. (2019) [36] reported no statistically significant failure data for the secondary outcome. In particular, Beier et al. (2012) reported 5 failures in 9 onlays and inlays against 23 failures in 538 indirect partial adhesive restorations on vital teeth with 12 years of follow-up, but the non-vital teeth population seemed too small to draw significant conclusions [34].

However, the lack of systematic long-term clinical data in the literature is partially justified by the considerable scientific effort that clinical trials represent. Moreover, the continuous evolution of clinical techniques may be responsible for the relatively difficult organization of the obtained scientific data. Regarding the pooled hazard ratio, the evaluated studies seemed all significant, and the value of 7.78 was partially confirmed by the high value of the pooled odds ratio.

The most frequent reasons for the failure of indirect partial composite restorations have been reported to be secondary caries and fractures of the restorative material and the non-covered cusps [52]. Moreover, the partial indirect ceramic restorations showed the predominant risk of loss of retention [54]. Therefore, the clinical durability of dentin-bonded restorations is strongly dependent on the degradation of the restorative material and the luting agent $[46,59]$. The adhesive bonding of restorations to dentin has been indicated to be weak and techniquesensitive [60, 69], especially for the proximal margins where the majority of secondary caries are diagnosed [60]. Typically, a tooth that requires endodontic treatment has lost a large volume of tissue and is more prone to fracture [15], besides having a more reduced retention area compared to vital teeth [54]. 
The loss of marginal ridges has been shown to reduce cuspal stiffness and, in the case of MOD cavities, this is to an extent of $63 \%$ [48]. Loss of water and weakened collagen cross-linking [70] strongly affect frailty through increased cuspal deflection during function, with a consequent higher occurrence of fractures $[57,71]$. Even endodontic irrigants have a negative impact on the physical properties of dentin, which makes it less suitable as a bonding substrate [67]. The difference in adhesive substrate to which the primers are applied may be predominant: hydrophilic dentin in vital teeth and sclerotic less water-containing dentin tissues in ETT [35]. Therefore, non-vital teeth are usually less prone to perceive increased load if not properly restored [72]. The adhesive techniques allow the preservation of residual tooth tissue, avoiding the creation of micromechanical retentions, but vital teeth characteristics are usually more favorable for long-term indirect adhesive partial restorations outcomes [73].

\section{Conclusions}

Within the limitations of this study, the risk of failure seems much higher for indirect partial adhesive restorations on ETT than for those on vital teeth.

Author contribution All authors have contributed significantly and are in agreement with this article.

Funding Open access funding provided by Universita degli Studi di Torino within the CRUI-CARE Agreement.

\section{Declarations}

Conflict of interest The authors declare no competing interests.

Open Access This article is licensed under a Creative Commons Attribution 4.0 International License, which permits use, sharing, adaptation, distribution and reproduction in any medium or format, as long as you give appropriate credit to the original author(s) and the source, provide a link to the Creative Commons licence, and indicate if changes were made. The images or other third party material in this article are included in the article's Creative Commons licence, unless indicated otherwise in a credit line to the material. If material is not included in the article's Creative Commons licence and your intended use is not permitted by statutory regulation or exceeds the permitted use, you will need to obtain permission directly from the copyright holder. To view a copy of this licence, visit http://creativecommons.org/licenses/by/4.0/.

\section{References}

1. Sorrentino R, Di Mauro MI, Ferrari M, Leone R, Zarone F (2016) Complications of endodontically treated teeth restored with fiber posts and single crowns or fixed dental prostheses-a systematic review. Clin Oral Invest 20:1449-1457
2. Demarco Dent Mater (2012) Manhart J, Chen H, Hamm G, Hickel R. (2004) Buonocore Memorial Lecture. Review of the clinical survival of direct and indirect restorations in posterior teeth of the permanent dentition. Oper Dent 29:481-508

3. Glazer B (2000) Restoration of endodontically treated teeth with carbon fiber posts - a prospective study. J Can Dent Assoc 66:613-618

4. Olivieri JG, Elmsmari F, Miro Q, Ruiz XF, Krell KV, Garcia-Font M, Duran-Sindreu F (2020) Outcome and survival of endodontically treated cracked posterior permanent teeth: a systematic review and meta-analysis. J Endod 46:455-463

5. da Rosa Rodolpho PA, Cenci MS, Donassollo TA, Loguércio AD, Demarco FF (2006) A clinical evaluation of posterior composite restorations: 17-year findings. J Dent 34(7):427-435

6. Pashley DH (1989) Dentin: a dynamic substrate-a review. Scanning Microsc 3:161-174

7. Pascon FM, Kantovitz KR, Sacramento PA, Nobre-dos-Santos M, Puppin-Rontani RM (2009) Effect of sodium hypochlorite on dentin mechanical properties. A review J Dent 37:903-908

8. Shetty S, Kahler SL, Kahler B (2017) Alkaline material effects on roots of teeth. Materials (Basel) 10(12):1412

9. Fernandes S, Dessai GS (2001) Factors affecting the fracture resistance of post-core reconstructed teeth: a review. Int J Prosthodont 14:355-363

10. Colman HL (1979) Restoration of endodontically treated teeth. Dent Clin North Am 23:647-662

11. Assif D, Gorfil C (1994) Biomechanical considerations in restoring endodontically treated teeth. J Prosthet Dent 71:565-567

12. Aquilino SA, Caplan DJ (2002) Relationship between crown placement and the survival of endodontically treated teeth. J Prosthet Dent 87:256-263

13. Seow LL, Toh CG, Wilson NH (2015) Strain measurements and fracture resistance of endodontically treated premolars restored with all-ceramic restorations. J Dent 43:126-132

14. Edelhoff D, Sorensen JA (2002) Tooth structure removal associated with various preparation designs for anterior teeth. J Prosthet Dent 87:503-509

15. Mannocci F, Cowie J (2014) Restoration of endodontically treated teeth. Br Dent J 216(6):341-346

16. Scotti N, Forniglia A, Tempesta RM, Comba A, Saratti CM, Pasqualini D, Alovisi M, Berutti E (2016) Effects of fiber-glass-reinforced composite restorations on fracture resistance and failure mode of endodontically treated molars. J Dent 53:82-87

17. Frankenberger R, Zeilinger I, Krech M, Morig G, Naumann M, Braun A, Kramer N, Roggendorf MJ (2015) Stability of endodontically treated teeth with differently invasive restorations: adhesive vs. non-adhesive cusp stabilization. Dent Mater 31(11):1312-20

18. Rocca GT, Daher R, Saratti CM, Sedlacek R, Suchy T, Feilzer AJ, Krejci I (2018) Restoration of severely damaged endodontically treated premolars: the influence of the endo-core length on marginal integrity and fatigue resistance of lithium disilicate CAD-CAM ceramic endocrowns. J Dent 68:41-50

19. Belleflamme MM, Geerts SO, Louwette MO, Grenade CF, Vanheusden AJ, Mainjot AK (2017) No post-no core approach to restore severely damaged posterior teeth: an up to 10-year retrospective study of documented endocrown cases. J Dent 63:1-7

20. Scotti N, Eruli C, Comba A, Paolino DS, Alovisi M, Pasqualini D, Berutti E (2015) Longevity of class 2 direct restorations in rootfilled teeth: a retrospective clinical study. J Dent 43(5):499-505

21. Strasding M, Sebestyen-Huvos E, Studer S, Lehner C, Jung RE, Sailer I (2020) Long-term outcomes of all-ceramic inlays and onlays after a mean observation time of 11 years. Quintessence Int 51:566-576

22. Skupien JA, Opdam N, Winnen R, Bronkhorst E, Kreulen C, Pereira-Cenci T, Huysmans MC (2013) A practice-based study 
on the survival of restored endodontically treated teeth. J Endod 39:1335-1340

23. Reiss B (2006) Clinical results of Cerec inlays in a dental practice over a period of 18 years. Int J Comput Dent 9:11-22

24. Vagropoulou GI, Klifopoulou GL, Vlahou SG, Hirayama H, Michalakis K (2018) Complications and survival rates of inlays and onlays vs complete coverage restorations: a systematic review and analysis of studies. J Oral Rehabil 45:903-920

25. Morimoto S, Rebello de Sampaio FB, Braga MM, Sesma N, Ozcan M (2016) Survival rate of resin and ceramic inlays, onlays, and overlays: a systematic review and meta-analysis. J Dent Res 95:985-994

26. Sampaio F, Ozcan M, Gimenez TC, Moreira M, Tedesco TK, Morimoto S (2019) Effects of manufacturing methods on the survival rate of ceramic and indirect composite restorations: a systematic review and meta-analysis. J Esthet Restor Dent 31:561-571

27. Liberati A, Altman DG, Tetzlaff J, Mulrow C, Gotzsche PC, Ioannidis JP, Clarke M, Devereaux PJ, Kleijnen J, Moher D (2009) The PRISMA statement for reporting systematic reviews and meta-analyses of studies that evaluate health care interventions: explanation and elaboration. PLoS Med 6:e1000100

28. Abduo J, Sambrook RJ (2018) Longevity of ceramic onlays: a systematic review. J Esthet Restor Dent 30:193-215

29. Landis JR, Koch GG (1977) The measurement of observer agreement for categorical data. Biometrics 33:159-174

30. Cumpston M, Li T, Page MJ, Chandler J, Welch VA, Higgins JP, Thomas J (2019) Updated guidance for trusted systematic reviews: a new edition of the Cochrane handbook for systematic reviews of interventions. Cochrane Database Syst Rev 10:ED000142

31. Tierney JF, Stewart LA, Ghersi D, Burdett S, Sydes MR (2007) Practical methods for incorporating summary time-to-event data into meta-analysis. Trials 8:16

32. Parmar MK, Torri V, Stewart L (1998) Extracting summary statistics to perform meta-analyses of the published literature for survival endpoints. Stat Med 17:2815-2834

33. Lo CK, Mertz D, Loeb M (2014) Newcastle-Ottawa Scale: comparing reviewers' to authors' assessments. BMC Med Res Methodol 14:45

34. Beier US, Kapferer I, Burtscher D, Giesinger JM, Dumfahrt H (2012) Clinical performance of all-ceramic inlay and onlay restorations in posterior teeth. Int J Prosthodont 25:395-402

35. van Dijken JW, Hasselrot L (2010) A prospective 15-year evaluation of extensive dentin-enamel-bonded pressed ceramic coverages. Dent Mater 26:929-939

36. Bresser RA, Gerdolle D, van den Heijkant IA, Sluiter-Pouwels LMA, Cune MS, Gresnigt MM (2019) Up to 12 years clinical evaluation of 197 partial indirect restorations with deep margin elevation in the posterior region. J Dent 91:103227

37. Stoll R, Cappel I, Jablonski-Momeni A, Pieper K, Stachniss V (2007) Survival of inlays and partial crowns made of IPS empress after a 10-year observation period and in relation to various treatment parameters. Oper Dent 32:556-563

38. Schulte AG, Vockler A, Reinhardt R (2005) Longevity of ceramic inlays and onlays luted with a solely light-curing composite resin. J Dent 33:433-442

39. Homsy F, Eid R, El Ghoul W, Chidiac JJ (2015) Considerations for altering preparation designs of porcelain inlay/onlay restorations for nonvital teeth. J Prosthodont 24:457-462

40. Studer SP, Wettstein F, Lehner C, Zullo TG, Scharer P (2000) Long-term survival estimates of cast gold inlays and onlays with their analysis of failures. J Oral Rehabil 27:461-472

41. Dioguardi M, Alovisi M, Crincoli V, Aiuto R, Malagnino G, Quarta C, Laneve E, Sovereto D, Lo Russo L, Troiano G et al (2020) Prevalence of the genus Propionibacterium in primary and persistent endodontic lesions: a systematic review. J Clin Med 9(3):739

42. Dioguardi M, Crincoli V, Laino L, Alovisi M, Sovereto D, Lo Muzio L, Troiano G (2020) Prevalence of bacteria of genus Actinomyces in persistent extraradicular lesions-systematic review. J Clin Med 9(2):457

43. Anshida VP, Kumari AR, Murthy CS, Anoop S (2020) Extracellular matrix degradationby host matrix metalloproteinases in restorative dentistry and endodontics: an overview. J Oral Maxillofac Pathol 24(2):352-360

44. Rechenberg DK, Zehnder M (2014) Molecular diagnostics in endodontics. Endod Top 30:51-65

45. Breschi L, Mazzoni A, Ruggeri A, Cadenaro M, Di Lenarda R, De Stefano DE (2008) Dental adhesion review: aging and stability of the bonded interface. Dent Mater 24:90-101

46. Maravic T, Mazzoni A, Comba A et al (2017) How stable is dentin as a substrate for bonding? Curr Oral Health Rep 4:248-257

47. Nagasiri R, Chitmongkolsuk S (2005) Long-term survival of endodontically treated molars without crown coverage: a retrospective cohort study. J Prosthet Dent 3(2):164-170

48. Reeh ES, Messer HH, Douglas WH (1989) Reduction in tooth stiffness as a result of endodontic and restorative procedures. $\mathrm{J}$ Endod 15:512-516

49. Mangani F, Marini S, Barabanti N, Preti A, Cerutti A (2015) The success of indirect restorations in posterior teeth: a systematic review of the literature. Minerva Stomatol 64(5):1-40

50. Vârlan C, Dimitriu B, Vârlan V, Bodnar D, Suciu I (2009) Current opinions concerning the restoration of endodontically treated teeth: basic principles. J Med Life 2(2):165-172

51. Caplan DJ, Kolker J, Rivera EM, Walton RE (2002) Relationship between number of proximal contacts and survival of root canal treated teeth. Int Endod J 35(2):193-199

52. Van Nieuwenhuysen J-P, D`1Hoore W, Carvalho J, Qvist V (2003) Long-term evaluation of extensive restorations in permanent teeth. J Dent 31:395-405

53. Tang $\mathrm{W}, \mathrm{Wu} \mathrm{Y}$, Smales RJ (2010) Identifying and reducing risks for potential fractures in endodontically treated teeth. J Endod 36(4):609-617

54. van Dijken JWV, Hasselrot L, Örmin A, Olofsson A-L (2001) Durability of extensive dentin-enamel-bonded ceramic coverages (IPS Empress). A 5-year follow-up. Eur J Oral Sci 109:222-229

55. Staehle HJ (1999) Minimally invasive restorative treatment. J Adhes Dent 1(3):67-84

56. Lin CL, Chang YH, Pa CA (2009) Estimation of the risk of failure for an endodontically treated maxillary premolar with MODP preparation and CAD/CAM ceramic restorations. J Endod 35(10):1391-1395

57. Assif D, Gorfil C (1994) Biomechanical considerations in restoring endodontically treated teeth. J Prosthet Dent 71:565-567

58. Scotti N, Cavalli G, Gagliani M, Breschi L (2017) New adhesives and bonding techniques. Why and when? Int J Esthet Dent. 12(4):524-535

59. Burke FJT (1995) The effect of variations in bonding procedure on fracture resistance of dentin-bonded all-ceramic crowns. Quintessence Int 26:293-300

60. Sjögren G, Molin M, van Dijken JWV (2004) A 10-year prospective evaluation of CAD/CAM-manufactured (Cerec) ceramic inlays cemented with a chemically cured or a dual-cured resin composite. Int J Prosthodont 17:241-246

61. Cuevas-Suárez CE, de Oliveira da Rosa WL, Vitti RP, da Silva AF, Piva E (2020) Bonding strength of universal adhesives to indirect substrates: a meta-analysis of in vitro studies. J Prosthodont 29(4):298-308

62. de Oliveira da Rosa Wellington Luiz, Piva Evandro, Fernandes da Silva Adriana (2015) Bond strength of universal adhesives: a systematic review and meta-analysis. J Dent 43(7):765-76 
63. Abo-Hamar SE, Hiller KA, Jung H, Federlin M, Friedl KH, Schmalz G (2005) Bond strength of a new universal self-adhesive resin luting cement to dentin and enamel. Clin Oral Investig 9(3): 161-167

64. Öztürk E, Bolay Ş, Hickel R, Ilie N (2013) Shear bond strength of porcelain laminate veneers to enamel, dentine and enamel-dentine complex bonded with different adhesive luting systems. J Dent 41(2):97-105

65. Shimada Y, Iwamoto N, Kawashima M, Burrow MF, Tagami J (2003) Shear bond strength of current adhesive systems to enamel, dentin and dentin-enamel junction region. Oper Dent 28(5):585-590

66. Demarco FF, Corrêa MB, Cenci MS, Moraes RR, Opdam NJ (2012) Longevity of posterior composite restorations: not only a matter of materials. Dent Mater 28(1):87-101

67. Abad-Coronel C, Naranjo B, Valdiviezo P (2019) Adhesive systems used in indirect restorations cementation: review of the literature. Dent J (Basel) 7(3):71

68. Benk J (2007) Conservative restorative treatment using a singlevisit, all-ceramic CAD/CAM system. Pract Proced Aesthet Dent 19(1):35-40

69. Scotti N, Comba A, Gambino A, Manzon E, Breschi L, Paolino D, Pasqualini D, Berutti E (2016) Influence of operator experience on non-carious cervical lesion restorations: clinical evaluation with different adhesive systems. Am J Dent 29(1):33-8

70. Pontius O, Nathanson D, Giordano R et al (2002) Survival rate and fracture strength of incisors restored with different post and core systems and endodontically treated incisors without coronoradicular reinforcement. J Endod 28:710-715

71. Grigoratos D, Knowles J, Ng YL, Gulabivala K (2001) Effect of exposing dentin to sodium hypochlorite and calcium hydroxide on its flexural strength and elastic modulus. Int Endod J 34:113-119

72. Randow K, Glantz PO (1986) On cantilever loading of vital and non-vital teeth. An experimental clinical study. Acta Odontol Scand 44:271-277

73. Mannocci F, Bertelli E, Sherriff M, Watson TF, Ford TR (2002) Three-year clinical comparison of survival of endodontically treated teeth restored with either full cast coverage or with direct composite restoration. J Prosthet Dent 88:297-301

Publisher's note Springer Nature remains neutral with regard to jurisdictional claims in published maps and institutional affiliations. 